\title{
Topography of the Polar Layered Deposits of Mars
}

\author{
Daniel Dzurisin and Karl R. Blasius \\ Division of Geological and Planetary Sciences, California Institute of Technology, Pasadena, California \\ 91125
}

\begin{abstract}
Synthesis of polar topographic data derived from the Mariner 9 radio occultation, ultraviolet spectrometer, and television imaging experiments provides new information on the behavior of polar volatiles and the topographic configuration of the martian polar layered deposits. Gentle slopes in the vicinity of the south pole may serve to shift the point of minimum annual solar insolation from the pole to a site within the perimeter of the offset residual frost cap. Localized defrosting which gives rise to the dark-banded appearance of both residual caps correlates with a series of outward-facing slopes descending from central topographic highs. Stability of the volatile involved apparently is largely insolation controlled. The south polar residual cap lies entirely higher (at lower pressure) than the northern cap, implying that the south residual cap is an unlikely site for any permanent surface deposit of solid carbon dioxide. Photogrammetric models of both residual caps reveal a series of regularly spaced topographic undulations descending from central topographic highs within the underlying layered deposits. Scarplike to troughlike in cross section, these features slope $1^{\circ}-5^{\circ}$ and are $100-1000 \mathrm{~m}$ in local relief. The south polar layered deposits lie almost entirely at higher elevations than those in the north. Total thickness of the deposits is inferred to be $1-2 \mathrm{~km}$ in the south and $4-6 \mathrm{~km}$ in the north.
\end{abstract}

\section{INTRODUCTION}

Mariner 9 has provided a wealth of new information for the polar regions of Mars. This paper deals specifically with polar topographic data, especially as they apply to the behavior of polar volatiles and to the topographic configuration of polar layered deposits. The effect of local heights and slopes on volatile stability in the polar regions is examined and discussed. Preliminary conclusions on the nature of polar volatiles based on theoretical considerations and incomplete topographic data [Cutts, 1973b; Murray and Malin, 1973b] are reexamined on the basis of more detailed topographic information.

Murray and Malin [1973a] and Cutts [1973a] have suggested that clues to the genesis of the polar layered deposits may be obtained from their present topographic configuration. We examine those authors' differing interpretations of the dark bands which transect both residual frost caps in light of a new semiquantitative topographic description of the underlying layered deposits.

\section{Data Description}

Mariner 9 provided four potential sources of topographic information for the martian polar regions: (1) $S$ band radio occultation, (2) infrared interferometer spectrometer, (3) ultraviolet spectrometer (UVS), and (4) television imaging. Unfavorable viewing geometry of the martian polar regions precludes the acquisition of reliable ground-based radar or $\mathrm{CO}_{2}$ pressure data.

The $S$ band radio occultation experiment provided 12 useful occultation points within the boundary of the south polar layered deposits and 3 within the northern deposits [Kliore et al., 1973]. Detailed analysis of polar topography is not possible from these data alone, owing to low spatial density of the occultation measurements. Although the infrared interferometer spectrometer has provided some data on equatorial and mid-latitude topography [Conrath et al., 1973], no polar topographic information is currently available.

Preliminary analysis of several hundred spectra from the

Copyright () 1975 by the American Geophysical Union.
Mariner 9 ultraviolet spectrometer has been completed by $\mathrm{K}$. Pang of the Jet Propulsion Laboratory and C. W. Hord of the University of Colorado. Analysis is continuing in an attempt to eliminate small perturbing effects apparently associated with local atmospheric inhomogeneities.

Finally, Mariner 9 returned more than 1100 television frames of a reas poleward of $65^{\circ}$ latitude, over half of high (B camera) resolution. Some of the B camera stereo images of the south polar residual frost cap were previously processed to produce high-resolution point elevation maps [Blasius, 1973]. Six more B frame photogrammetric models are presented and are combined with wide-angle $A$ frame models to produce generalized topographic maps of the north and south polar residual frost caps and underlying layered deposits.

\section{South Polar Region}

\section{Large-Scale Topography}

Both the radio occultation and the ultraviolet spectrometer data in the south polar region suggest that the area is topographically complex [Kliore et al., 1973; K. Pang and C. W. Hord, personal communication, 1974] (see Figure 1, Table 1). Note especially the existence of an arcuate scarp approximately $1300 \mathrm{~km}$ long centered near $83^{\circ} \mathrm{S}, 266^{\circ} \mathrm{W}$ (see upper right of Figure 1). Wilhelms [1973] has interpreted the feature as the rim of a major impact basin roughly $850 \mathrm{~km}$ in diameter, and Pang [1972] has suggested that the basin may be responsible for the offset of the south polar residual frost cap. For a perfect sphere the point of minimum annual solar insolation lies at the point(s) on the surface whose local normal is parallel to the spin axis. Should the topographic expression of an ancient impact basin be preserved in the vicinity of the pole, its slopes would serve to shift the point of minimum annual solar insolation away from the rotational pole to some lower latitude. The offset of the south polar residual cap is consistent with a small local slope at the pole toward the center of the basin.

K. Pang and C. W. Hord (personal communication, 1974) report that preliminary analysis of the south polar UVS data suggests a broad quasi-circular depression approximately $3 \mathrm{~km}$ deep which correlates with the location of the presumed im- 


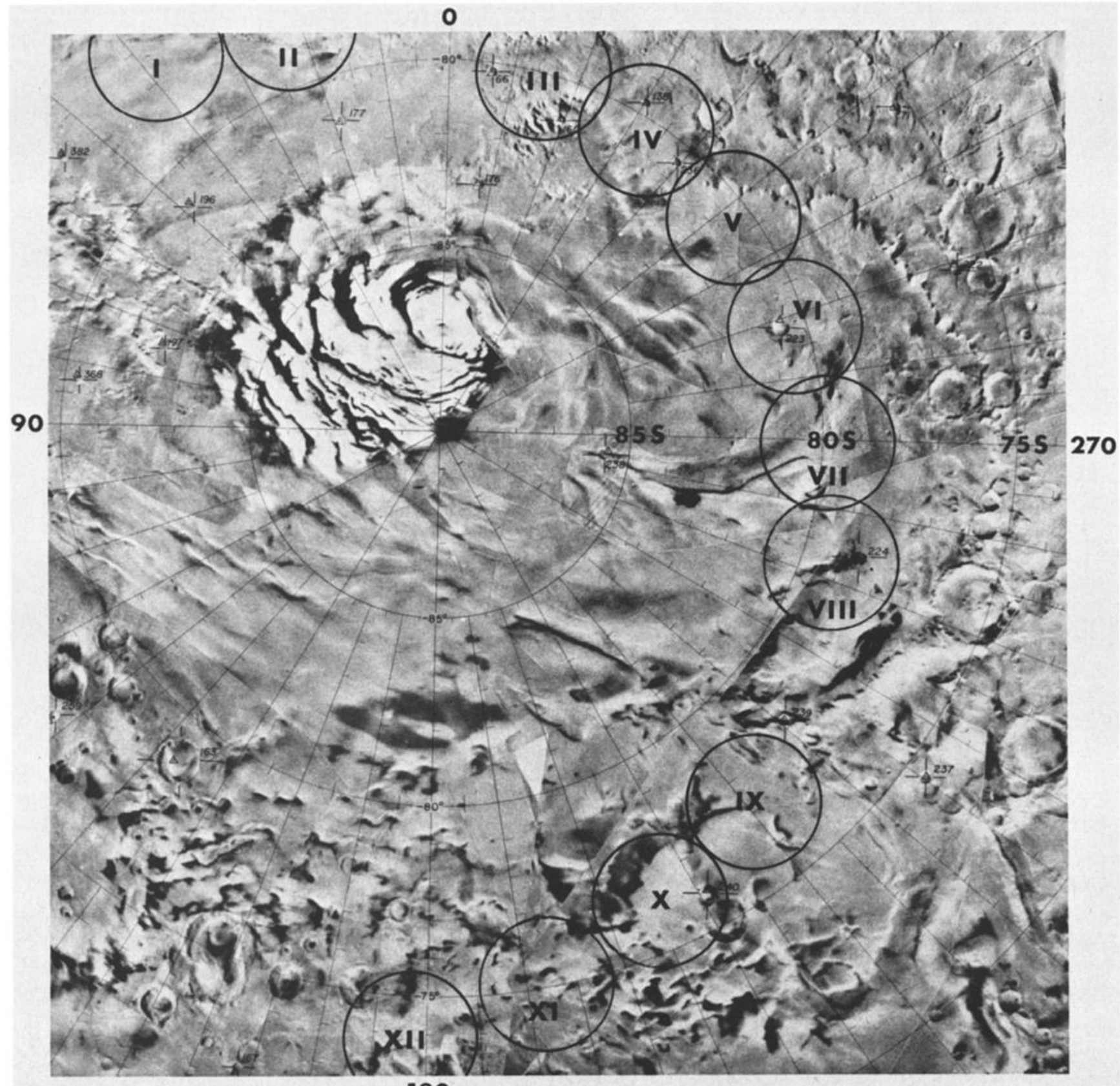

180

Fig. 1. Enlarged segment of the United States Geological Survey semicontrolled photomosaic of the region poleward of $65^{\circ} \mathrm{S}$ showing the planimetric configuration of the residual polar frost cap and the polar layered deposits. Circles enclose locations of radio occultation-derived radii measurements (see Table 1). Small triangles on the map denote points in the Mariner 9 control net used to establish the system of martian coordinates. Original scale of the USGS photomosaic was $1: 5,000,000$.

pact basin. A local slope of about $0.5^{\circ}$ inward toward the basin's center is indicated at the pole. Modeling errors apparently associated with local atmospheric inhomogeneities have been recognized, however, and may contribute to the apparent relief of the basin. Radio occultation data near the basin (Figure 1, Table 1) suggest a broad depression about 1 km deep but do not sample the basin's center. Although details of the basin's topography remain unresolved at this time, we adopt the UVS result of about $3 \mathrm{~km}$ maximum depth in subsequent discussions.

In addition to the large-scale UVS and occultation-derived data, a photogrammetric model of the residual south polar frost cap has been prepared from wide-angle $A$ camera photography (model A of Table 2; Table 3). For this and other models to be presented, relative elevations of a network of small features visible in both frames of Mariner 9 stereo pairs have been calculated from basic photogrammetric principles according to a recently developed analytic scheme for stereo analysis of spacecraft images [Blasius, 1973]. Topographic contours have then been interpolated between points to produce conventional topographic maps. Since no ground control points of known elevation are available in the polar regions, imprecisely known orbital and viewing parameters must be used to establish a reference datum for each model. An estimate of the tilt uncertainty obtained by comparing several overlapping models (not all in the polar regions) in- 


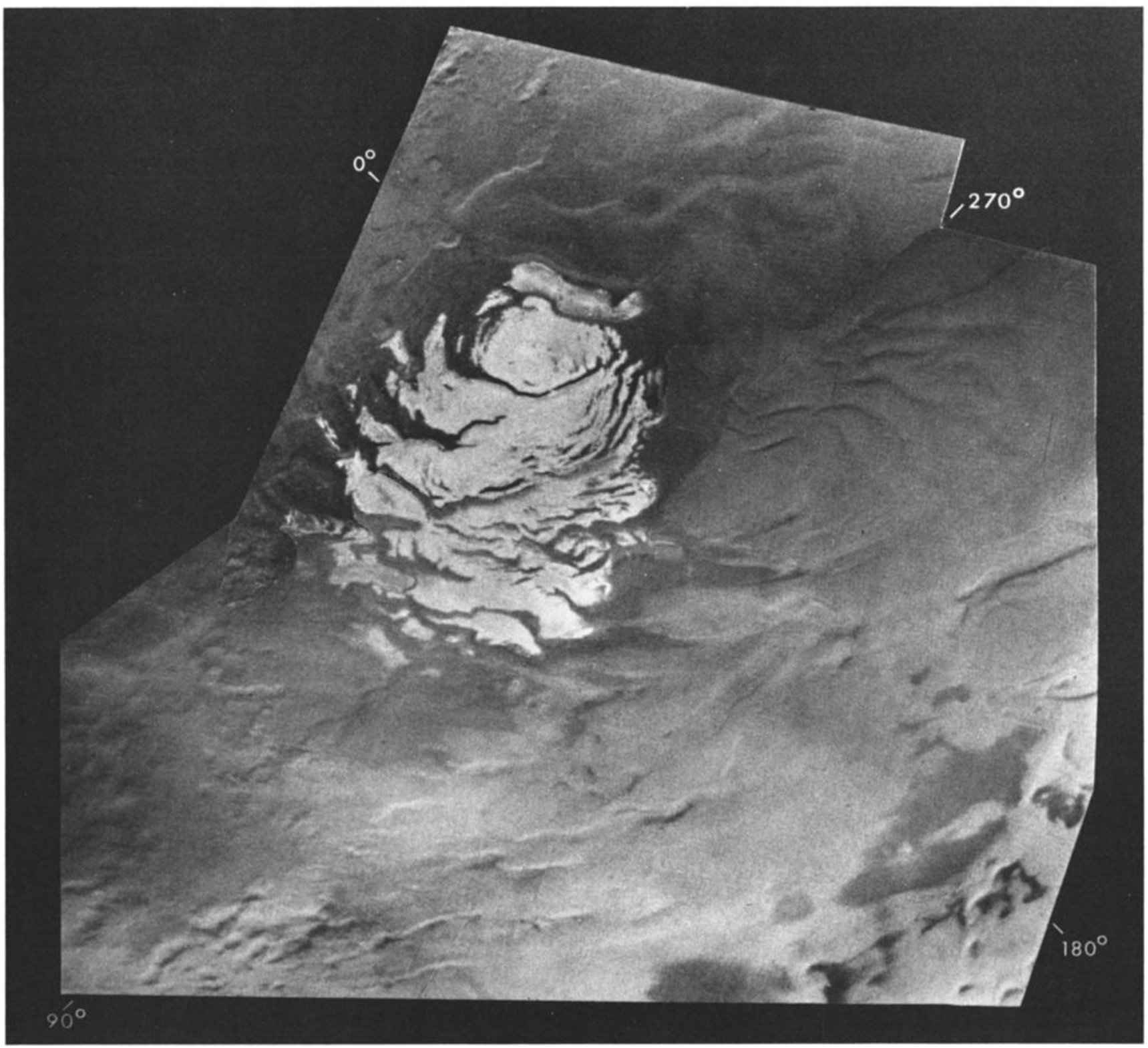

Fig. 2. Photomosaic of the south polar residual frost cap at A frame resolution. It is argued in the text that the dark bands arise from selective defrosting of a series of outward-facing slopes descending from a central topographic high near $87^{\circ} \mathrm{S}, 0^{\circ} \mathrm{W}$. Two photographs used in the mosaic have been computer enhanced at the Image Processing Lab of NASA's Jet Propulsion Laboratory.

TABLE 1. Polar Occultation Points [From Kliore et al., 1973]

\begin{tabular}{cc}
\hline Point & Radius, km \\
\hline South Polar Region (Figure I) & 331.5 \\
I-408X (noisy) & 3380.9 \\
II-410X (noisy) & 3383.9 \\
III-414X (noisy) & 3379.4 \\
IV-416X & 3379.8 \\
V-418X (noisy) & 3379.9 \\
VI-420X (noisy) & 3380.1 \\
VII-422XX (noisy) & 3380.0 \\
VIII-424X (nois & 3381.4 \\
IX-428X (noisy) & 3381.9 \\
X-430X (noisy) & 3380.6 \\
XI-432X (noisy) & 3383.8 \\
XII-434X North Polar Region (Figure 15) \\
North \\
XIII-374N (noisy) & 3376.6 \\
XIV-376N & 3376.8 \\
XV-378N & 3378.1 \\
\hline
\end{tabular}

dicates that regional tilts can disagree by as much as $2.5^{\circ}$. Figures 2 and 3 combine the south polar $A$ frame information with high-resolution $B$ frame models to be discussed in a later section. An attempt has been made to blend the two sources of information into a generalized topographic map by adjusting the tilts of the B frame models within uncertainty limits to achieve internal consistency.

Figure 3 reveals what appears to be a broad, domical form centered near $87^{\circ} \mathrm{S}, 0^{\circ} \mathrm{W}$. Since the residual frost is interrupted by numerous defrosted bands, we assume that the frost is relatively thin $(<100 \mathrm{~m})$ and conforms to topography of the underlying layered deposits. Details of high-resolution models outlined in Figure 3 suggest that the deposits exhibit a series of topographic undulations descending from the central high near $87^{\circ} \mathrm{S}, 0^{\circ} \mathrm{W}$. Slopes associated with these features are generally outward-facing from the central high. They are not exclusively equatorward-facing, since the topographic high is slightly offset from the rotational pole. 


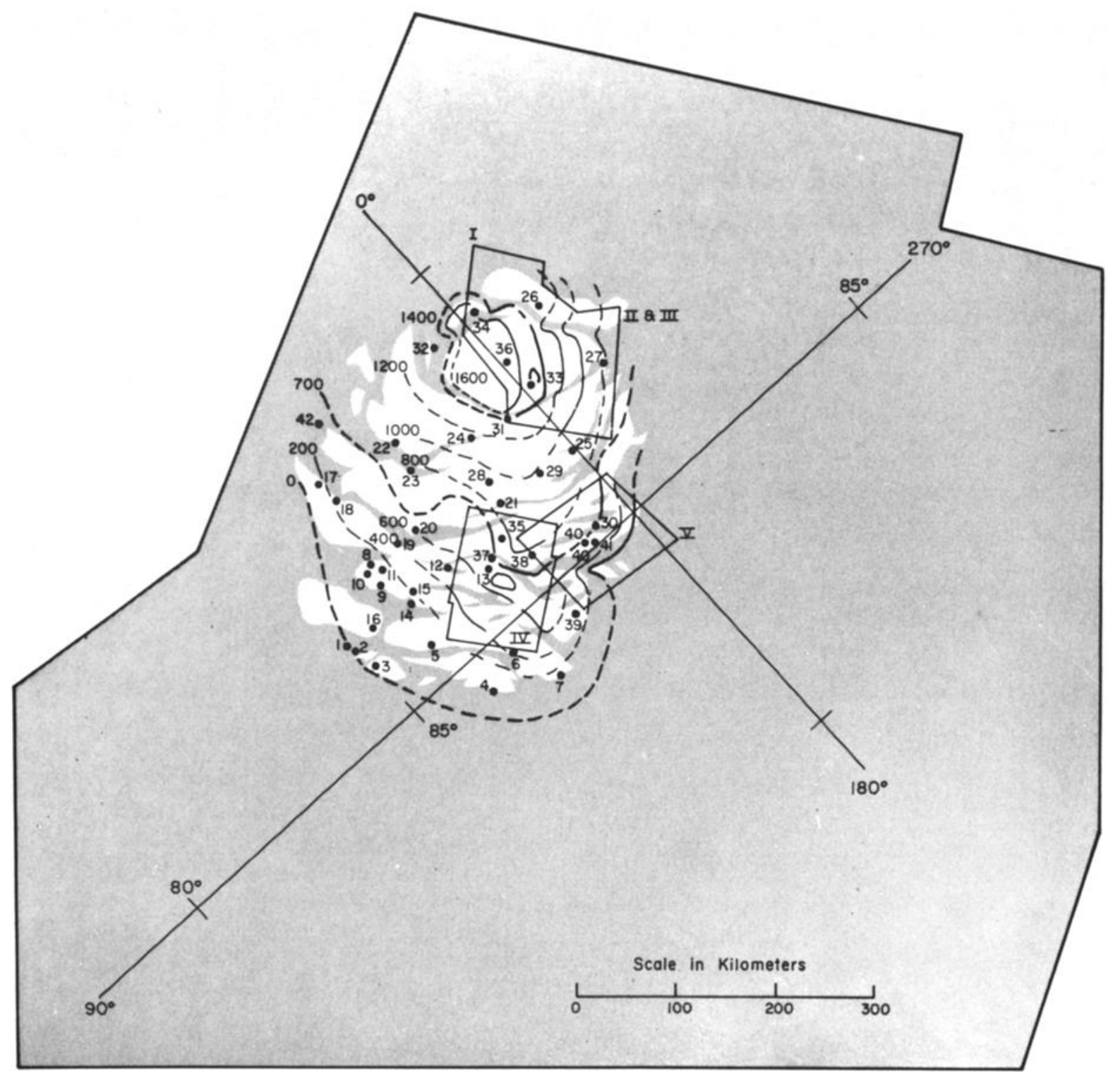

Fig. 3. Generalized topographic map of the south polar residual frost cap. The map was constructed by combining information from a single A frame photogrammetric model (model A) with that from five high-resolution B frame models. Locations of the B frame models have been outlined to illustrate the areas for which high-resolution information is available. Point elevations for the A frame model are listed in Table 3. Planetary curvature has been removed from the models by assuming a spherical planet with a radius of $3382 \mathrm{~km}$. Note irregular contour interval; contours labeled in meters.

TABLE 2. Stereo Models

\begin{tabular}{|c|c|c|c|c|c|}
\hline Model & Photo DAS & $\begin{array}{l}\text { Approximate } \\
\text { Location }\end{array}$ & $\begin{array}{c}\text { Ground } \\
\text { Resolution } \\
\text { (Per } 2 \text { Picture } \\
\text { Elements), m }\end{array}$ & $\begin{array}{c}\text { Estimated } \\
\text { Elevation } \\
\text { Uncertainty, } \\
\text { m }\end{array}$ & $\begin{array}{c}\text { Observed } \\
\text { Elevation } \\
\text { Uncertainty, } \\
\mathbf{m}\end{array}$ \\
\hline I & $\begin{array}{l}6029873 \\
3717850\end{array}$ & $\begin{array}{c}85.7^{\circ} \mathrm{S} \\
354.5^{\circ} \mathrm{W}\end{array}$ & $\begin{array}{l}227 \\
247\end{array}$ & 80 & 65 \\
\hline II & $\begin{array}{l}3466690 \\
3574350\end{array}$ & $\begin{array}{c}87.3^{\circ} \mathrm{S} \\
344.5^{\circ} \mathrm{W}\end{array}$ & $\begin{array}{l}260 \\
267\end{array}$ & 75 & 65 \\
\hline III & $\begin{array}{l}7791983 \\
3574350\end{array}$ & $\begin{array}{c}87.3^{\circ} \mathrm{S} \\
344.5^{\circ} \mathrm{W}\end{array}$ & $\begin{array}{l}233 \\
267\end{array}$ & 85 & 85 \\
\hline IV & $\begin{array}{l}3466620 \\
7900063\end{array}$ & $\begin{array}{l}86.7^{\circ} \mathrm{S} \\
83.6^{\circ} \mathrm{W}\end{array}$ & $\begin{array}{l}293 \\
207\end{array}$ & 80 & 75 \\
\hline v & $\begin{array}{l}6784823 \\
9698649\end{array}$ & $\begin{array}{l}89.0^{\circ} \mathrm{S} \\
90.0^{\circ} \mathrm{W}\end{array}$ & $\begin{array}{l}227 \\
213\end{array}$ & 85 & 80 \\
\hline VI & $\begin{array}{l}13352795 \\
13463258\end{array}$ & $\begin{array}{r}79.6^{\circ} \mathrm{N} \\
343.3^{\circ} \mathrm{W}\end{array}$ & $\begin{array}{l}660 \\
473\end{array}$ & 250 & 250 \\
\hline $\mathbf{A}$ & $\begin{array}{l}8295814 \\
8331864\end{array}$ & $90^{\circ} \mathrm{S}$ & $\begin{array}{l}1940 \\
1900\end{array}$ & 750 & 800 \\
\hline B & $\begin{array}{l}13317545 \\
13353320\end{array}$ & $90^{\circ} \mathrm{N}$ & $\begin{array}{l}5920 \\
5727\end{array}$ & 2500 & 2500 \\
\hline
\end{tabular}




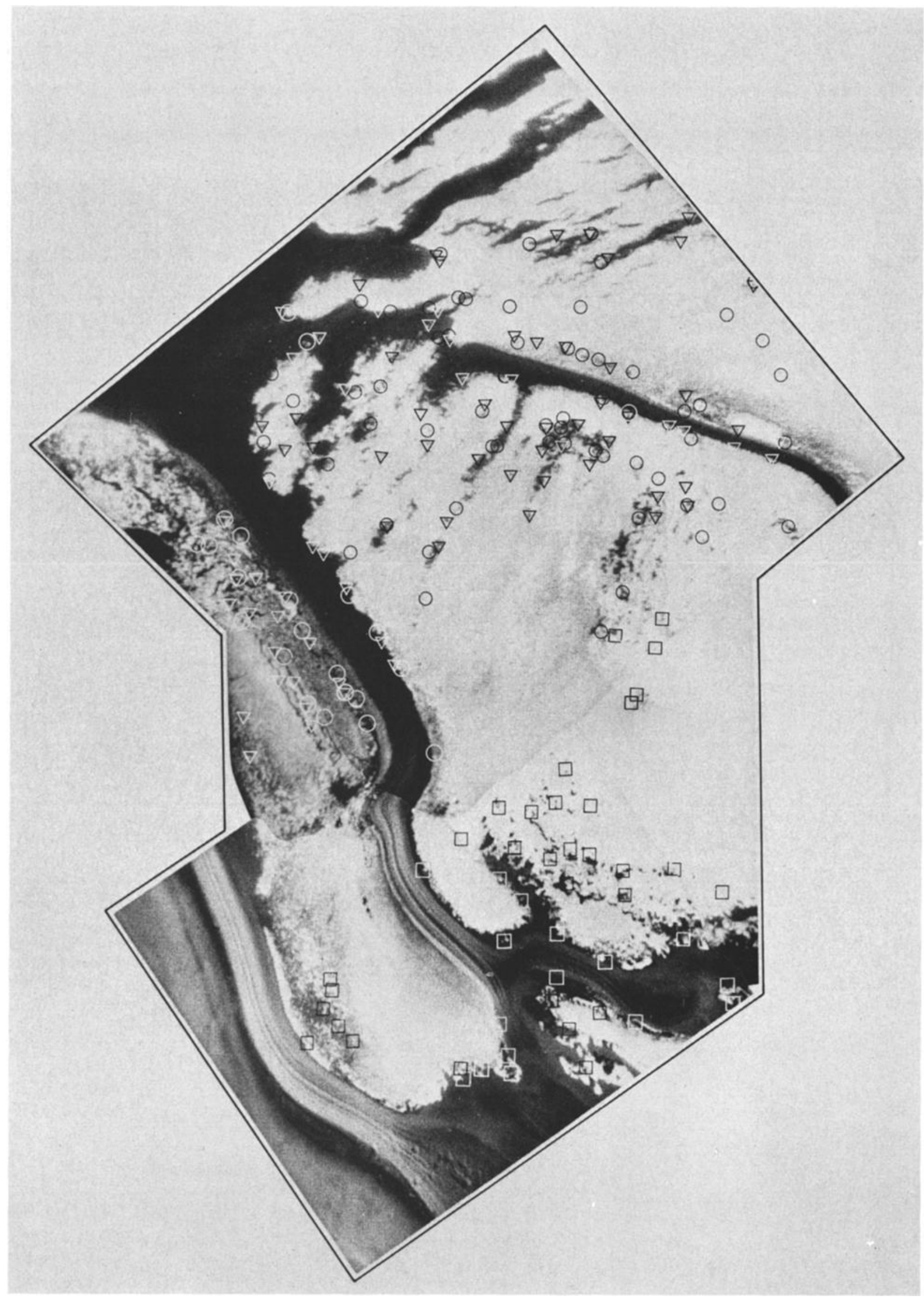

Fig. 4. Photomosaic of an area centered at $86.5^{\circ} \mathrm{S}, 0^{\circ} \mathrm{W}$ for which three high-resolution photogrammetric models have been constructed (Figures $5,7,8$ ). Squares, triangles, and circles enclose point features for which relative elevations have been calculated in models I, II, and III, respectively. 

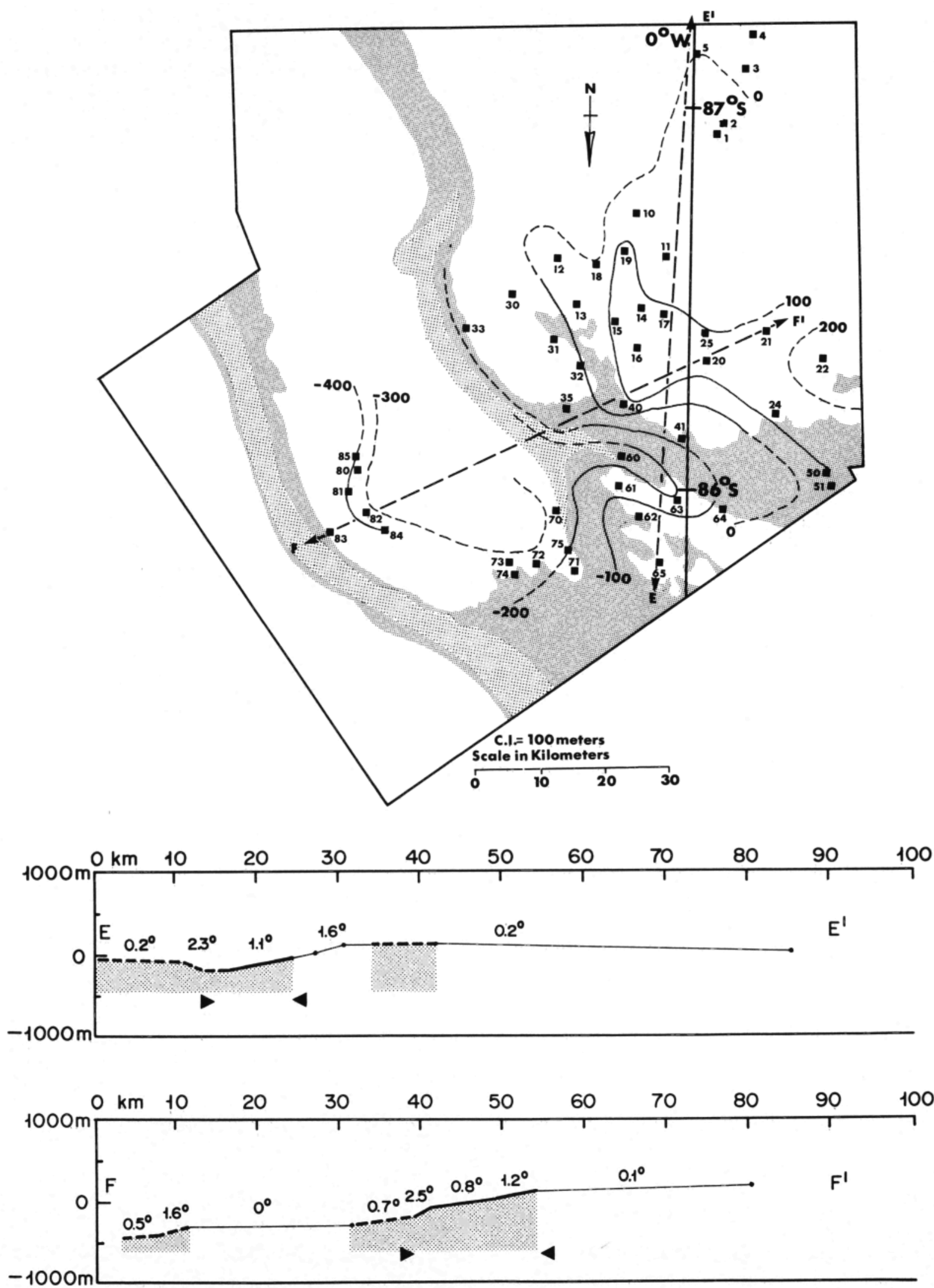

Fig. 5. Model I. Photogrammetric model of an area centered at $86^{\circ} \mathrm{S}, 0^{\circ} \mathrm{W}$ with associated profiles. Note that the scale of the profiles has been slightly expanded relative to the scale of the photomosaic. Relative elevations for the locations indicated by numbered squares are listed in Table 4; vertical exaggeration in the profiles is $10: 1$. Areas in the profiles bounded by triangles are those in which layers are visible in the best versions of the images; some may not be distinguishable in reproductions. Similarly, stippled areas in the profiles are those which exhibit partial or total defrosting in the best available versions of the photographs. Stippling in the model itself corresponds roughly to relatively low albedo areas in the photomosaic and should be ussed for visual orientation only. 


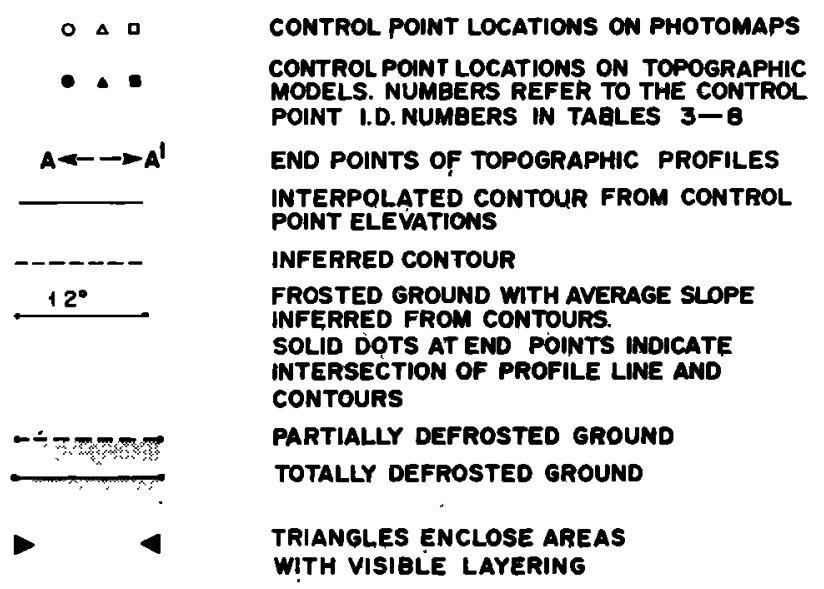

Fig. 6. Key to topographic models.

TABLE 3. Stereo Model A

\begin{tabular}{cccccc}
\hline $\begin{array}{c}\text { Control } \\
\text { Point }\end{array}$ & $\begin{array}{c}\text { Elevation, } \\
\mathrm{m}\end{array}$ & $\begin{array}{c}\text { Control } \\
\text { Point }\end{array}$ & $\begin{array}{c}\text { Elevation, } \\
\mathrm{m}\end{array}$ & $\begin{array}{c}\text { Control } \\
\text { Point }\end{array}$ & $\begin{array}{c}\text { Elevation, } \\
\mathrm{m}\end{array}$ \\
\hline 1 & 0 & 15 & 700 & 29 & -1200 \\
2 & 100 & 16 & 300 & 30 & 1200 \\
3 & 0 & 17 & 200 & 31 & 1500 \\
4 & 500 & 18 & 700 & 32 & 1700 \\
5 & 400 & 19 & 800 & 33 & 1700 \\
6 & 1400 & 20 & 900 & 34 & 2200 \\
7 & 400 & 21 & 1200 & 35 & 1600 \\
8 & 600 & 22 & 1600 & 36 & 1900 \\
9 & 700 & 23 & 700 & 37 & 1200 \\
10 & 500 & 24 & 800 & 38 & 1300 \\
11 & 700 & 25 & 1600 & 39 & 1500 \\
12 & 800 & 26 & 2200 & 40 & 1500 \\
13 & 1200 & 27 & 1900 & 41 & 1200 \\
14 & 700 & 28 & 1300 & 42 & 1700 \\
\hline
\end{tabular}

Taken together, the occultation, UVS, and A frame photogrammetric data indicate that the south polar layered deposits lie at planetocentric distances ranging from 3378 to $3383 \mathrm{~km}$, with an absolute uncertainty of about $2 \mathrm{~km}$. Similarly, the south polar residual frost cap lies at planetocentric distances ranging from 3381 to $3383 \mathrm{~km}$.
Associated surface pressures above the layered deposits and residual frost can be calculated by assuming that the atmosphere behaves hydrostatically and as an ideal gas. Kliore et al. [1973] have shown that the lapse rate of the martian atmosphere near the poles is roughly half of the adiabatic lapse rate. Thus

$$
p(z)=p\left(z_{0}\right)\left(\frac{T\left(z_{0}\right)-\Gamma \Delta z}{T\left(z_{0}\right)}\right)^{m_{0} / R \Gamma}
$$

where

$p(z)$ atmospheric pressure at height $z$;

$T(z)$ atmospheric temperature at height $z$;

$z_{0}$ reference height of known pressure, temperature, equal to $z-\Delta z$;

$m$ atmospheric molecular weight;

$g$ martian gravitational acceleration, equal to 370 $\mathrm{cm} / \mathrm{s}^{2}$;

$R$ universal gas constant, equal to $8.31 \times 10^{7}$ $\mathrm{ergs} / \mathrm{mol} /{ }^{\circ} \mathrm{K}$;

$\Gamma$ atmospheric lapse rate, approximately equal to $2.0^{\circ} \mathrm{K} / \mathrm{km}$.

In order to minimize errors, pressures have been calculated relative to both the 4.5-mbar equipotential surface computed by Woiceshyn [1974] and the 6.1-mbar isobaric surface computed by Cain et al. [1973]. Temperatures at both levels were assigned from the occultation data of Kliore et al. [1973]. Resulting pressures agree in all cases to within $0.6 \mathrm{mbar}$.

Surface pressures above the south polar layered deposits are calculated to range from 3.8 to 5.0 mbar, with an uncertainty of about 1.0 mbar. Similarly, pressure above the southern residual frost cap ranges from about 3.8 to $4.3 \mathrm{mbar}$. The major source of error in these calculations is most likely to be the uncertainty in absolute height associated with errors in the regional tilt of the $\mathbf{A}$ frame photogrammetric model. The quoted uncertainty of 1 mbar corresponds to our previous estimate of about $2-\mathrm{km}$ uncertainty in absolute height determinations.

\section{Small-Scale Topography}

Five new high-resolution photogrammetric models in the south polar region have now been completed (Figures 4-12; Tables 2, 4-8). Estimated uncertainties in relative elevations of

TABLE 4. Stereo Model 1

\begin{tabular}{cccccc}
\hline $\begin{array}{c}\text { Control } \\
\text { Point }\end{array}$ & $\begin{array}{c}\text { Elevation Relative } \\
\text { to Point 32, } \\
\mathbf{m}\end{array}$ & $\begin{array}{c}\text { Control } \\
\text { Point }\end{array}$ & $\begin{array}{c}\text { Elevation Relative } \\
\text { to Point 32, } \\
\mathbf{m}\end{array}$ & $\begin{array}{c}\text { Control } \\
\text { Point }\end{array}$ & $\begin{array}{c}\text { Elevation Relative } \\
\text { to Point 32, } \\
\text { m }\end{array}$ \\
\hline 1 & 80 & 21 & 170 & 63 & -190 \\
2 & 50 & 22 & 240 & 64 & -50 \\
3 & -30 & 24 & 140 & 65 & -60 \\
4 & -130 & 30 & -70 & 70 & -230 \\
5 & 0 & 31 & -20 & 71 & -130 \\
10 & 60 & 32 & 0 & 72 & -280 \\
11 & 60 & 33 & -60 & 73 & -280 \\
13 & 10 & 35 & -70 & 74 & -260 \\
14 & 100 & 40 & 90 & 75 & -200 \\
15 & 120 & 41 & -100 & 80 & -410 \\
16 & 160 & 50 & 90 & 81 & -380 \\
17 & 120 & 51 & 60 & 82 & -290 \\
18 & 0 & 60 & -240 & 83 & -440 \\
19 & 130 & 61 & -120 & 84 & -380 \\
20 & 120 & 62 & -30 & 85 & -450 \\
\hline
\end{tabular}


TABLE 5. Stereo Model II

\begin{tabular}{cccccc}
\hline $\begin{array}{c}\text { Control } \\
\text { Point }\end{array}$ & $\begin{array}{c}\text { Elevation Relative } \\
\text { to Point 79, } \\
\mathbf{m}\end{array}$ & $\begin{array}{c}\text { Control } \\
\text { Point }\end{array}$ & $\begin{array}{c}\text { Elevation Relative } \\
\text { to Point 79, } \\
\text { m }\end{array}$ & $\begin{array}{c}\text { Control } \\
\text { Point }\end{array}$ & $\begin{array}{c}\text { Elevation Relative } \\
\text { to Point 79, } \\
\text { m }\end{array}$ \\
\hline 1 & -375 & 74 & 200 & 114 & -460 \\
8 & -340 & 75 & 0 & 115 & -400 \\
13 & -350 & 77 & -85 & 117 & -175 \\
16 & -350 & 78 & -50 & 121 & -350 \\
19 & -300 & 79 & 0 & 123 & 0 \\
23 & -440 & 83 & -115 & 124 & -360 \\
25 & -400 & 85 & -420 & 125 & -330 \\
32 & -275 & 86 & -435 & 128 & -430 \\
35 & -260 & 87 & -525 & 131 & -460 \\
36 & -180 & 88 & -75 & 135 & -220 \\
37 & -200 & 89 & -75 & 140 & -125 \\
38 & -170 & 90 & -75 & 147 & 100 \\
41 & -275 & 91 & 75 & 151 & 40 \\
43 & -250 & 92 & -75 & 154 & 100 \\
45 & -100 & 93 & 110 & 155 & 160 \\
46 & -325 & 95 & 135 & 156 & -25 \\
48 & -325 & 96 & -360 & 157 & 10 \\
52 & -285 & 97 & -380 & 158 & -70 \\
54 & -240 & 98 & -485 & 161 & -75 \\
57 & -260 & 99 & -545 & 163 & -80 \\
58 & -215 & 100 & 10 & 166 & -180 \\
59 & -160 & 103 & 60 & 167 & -175 \\
62 & -150 & 104 & -220 & 168 & -200 \\
64 & -70 & 105 & -120 & 176 & -315 \\
68 & 75 & 110 & -450 & 178 & -250 \\
69 & -20 & 111 & -180 & 183 & -50 \\
71 & 115 & 112 & -500 & & \\
72 & 110 & 113 & -390 & & \\
\hline
\end{tabular}

TABLE 6. Stereo Model III

\begin{tabular}{|c|c|c|c|c|c|}
\hline $\begin{array}{l}\text { Control } \\
\text { Point }\end{array}$ & $\begin{array}{c}\text { Elevation Relative } \\
\text { to Point } 34, \\
\text { m }\end{array}$ & $\begin{array}{c}\text { Control } \\
\text { Point }\end{array}$ & $\begin{array}{c}\text { Elevation Relative } \\
\text { to Point } 34 \text {, } \\
\text { m }\end{array}$ & $\begin{array}{l}\text { Control } \\
\text { Point }\end{array}$ & $\begin{array}{c}\text { Elevation Relative } \\
\text { to Point } 34 \\
\text { m }\end{array}$ \\
\hline 1 & 100 & 34 & 0 & 66 & -1170 \\
\hline 2 & -70 & 35 & -170 & 67 & -1150 \\
\hline 3 & -50 & 36 & -220 & 68 & -1160 \\
\hline 4 & -410 & 37 & -100 & 69 & -720 \\
\hline 5 & -520 & 38 & -100 & 70 & -10 \\
\hline 6 & -730 & 39 & 70 & 71 & 90 \\
\hline 7 & -770 & 40 & 60 & 72 & -1150 \\
\hline 8 & -810 & 42 & -370 & 73 & -1270 \\
\hline 9 & -850 & 43 & -280 & 74 & -1360 \\
\hline 10 & -190 & 44 & -370 & 75 & -1230 \\
\hline 11 & 210 & 45 & 440 & 80 & 30 \\
\hline 12 & 240 & 46 & -130 & 81 & 450 \\
\hline 13 & 110 & 47 & -140 & 82 & 3 \\
\hline 14 & 190 & 50 & -130 & 83 & 280 \\
\hline 15 & -280 & 51 & -510 & 84 & -200 \\
\hline 20 & 650 & 53 & -890 & 85 & -330 \\
\hline 21 & 10 & 54 & -830 & 86 & 10 \\
\hline 22 & -700 & 55 & -680 & 87 & -480 \\
\hline 23 & -1160 & 56 & -680 & 88 & -120 \\
\hline 24 & -820 & 57 & -490 & 90 & 120 \\
\hline 25 & -430 & 58 & -690 & 91 & 300 \\
\hline 26 & -400 & 59 & -470 & 92 & 480 \\
\hline 27 & 130 & 60 & -330 & 93 & 680 \\
\hline 28 & 500 & 61 & -450 & 94 & 620 \\
\hline 29 & 1170 & 62 & -970 & 95 & 460 \\
\hline 30 & 140 & 63 & -1030 & 96 & 740 \\
\hline 31 & -190 & 64 & -1090 & 97 & 800 \\
\hline 32 & -930 & 65 & -1240 & 98 & 940 \\
\hline 33 & -600 & & & & \\
\hline
\end{tabular}



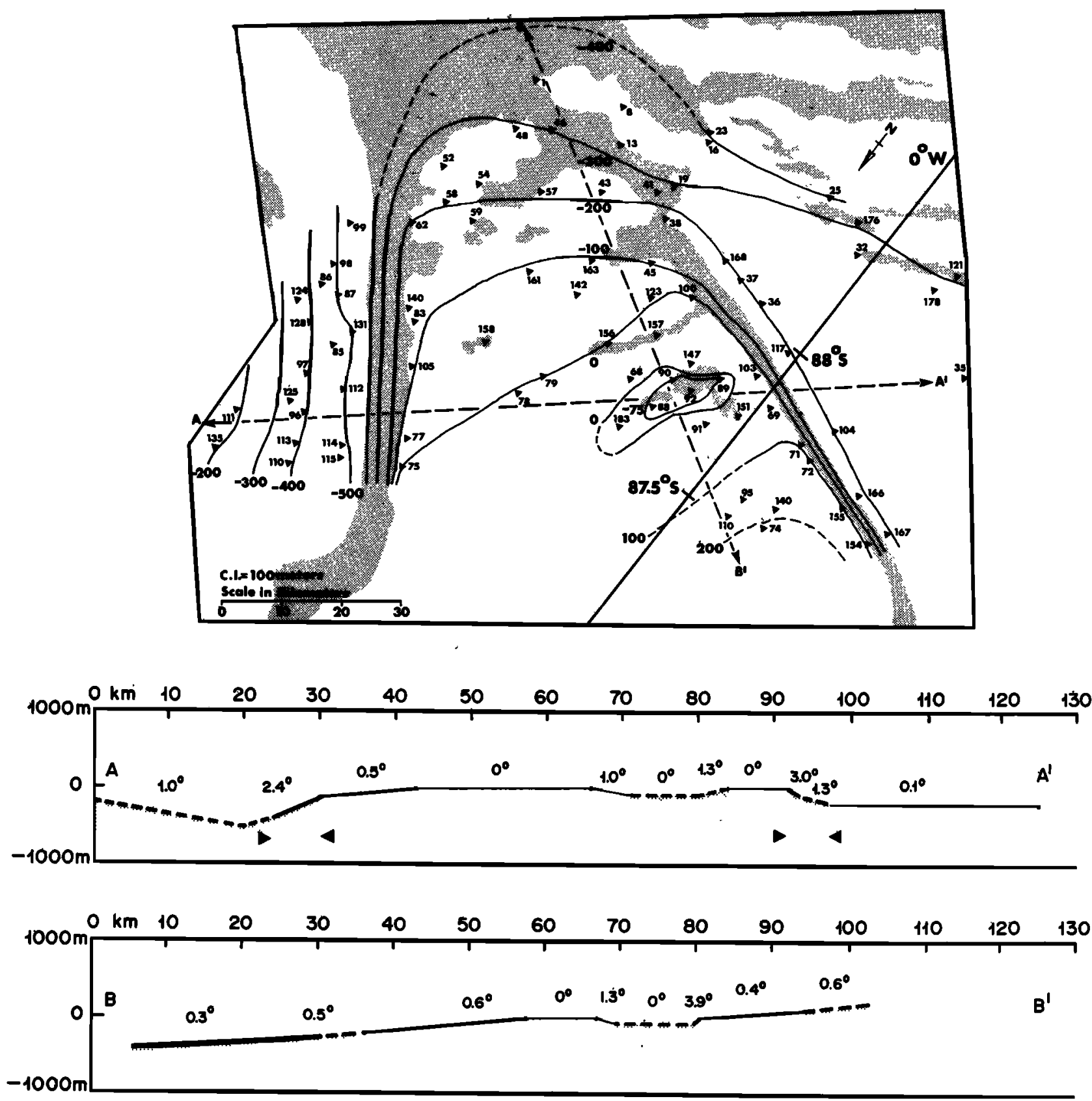

Fig. 7. Model II. Photogrammetric model of an area centered at approximately $88^{\circ} \mathrm{S}, 0^{\circ} \mathrm{W}$, which illustrates the morphologies associated with dark bands which are characteristic of both residual polar frost caps. Topographic profiles are drawn with a vertical exaggeration of $10: 1$ and are based on the model's interpolated contours. Numbered triangles indicate locations for which relative elevations have been calculated (Table 5). Note the evidence for topographically controlled defrosting within the dark bands. Horizontal scale of profiles is slightly expanded relative to photomosaic. Contour interval is $100 \mathrm{~m}$.

any two points in a given data network have been calculated from equation (13) of Blasius [1973] and are listed for each of the models in Table 2. Also included are ground resolutions for each photographi involved.

The significance of the tilt uncertainty already discussed is apparent in the profiles accompanying models I-V. Cutts [1973a] has proposed that some of the arcuate dark bands which transect both residual frost caps are erosional troughs associated with complex polar wind patterns, while Murray and Malin [1973a] have interpreted them as a series of constructional scarps perhaps associated with wandering of the martian spin axis relative to the surface. In an area where the maximum observed slopes are of the order of a few degrees, an uncertainty in the regional tilt of the same magnitude makes the distinction between scarps and troughs a difficult one to draw. (The terms scarp and trough are used here for convenience, even though the observed features are extremely gentle by terrestrial standards.) In several of the profiles, however, no reasonable adjustment of the regional tilt allows one to interpret the discernible topographic features as exclusively troughs or exclusively scarps. Thus the south polar layered deposits exhibit features ranging from scarps to nearly sym- 

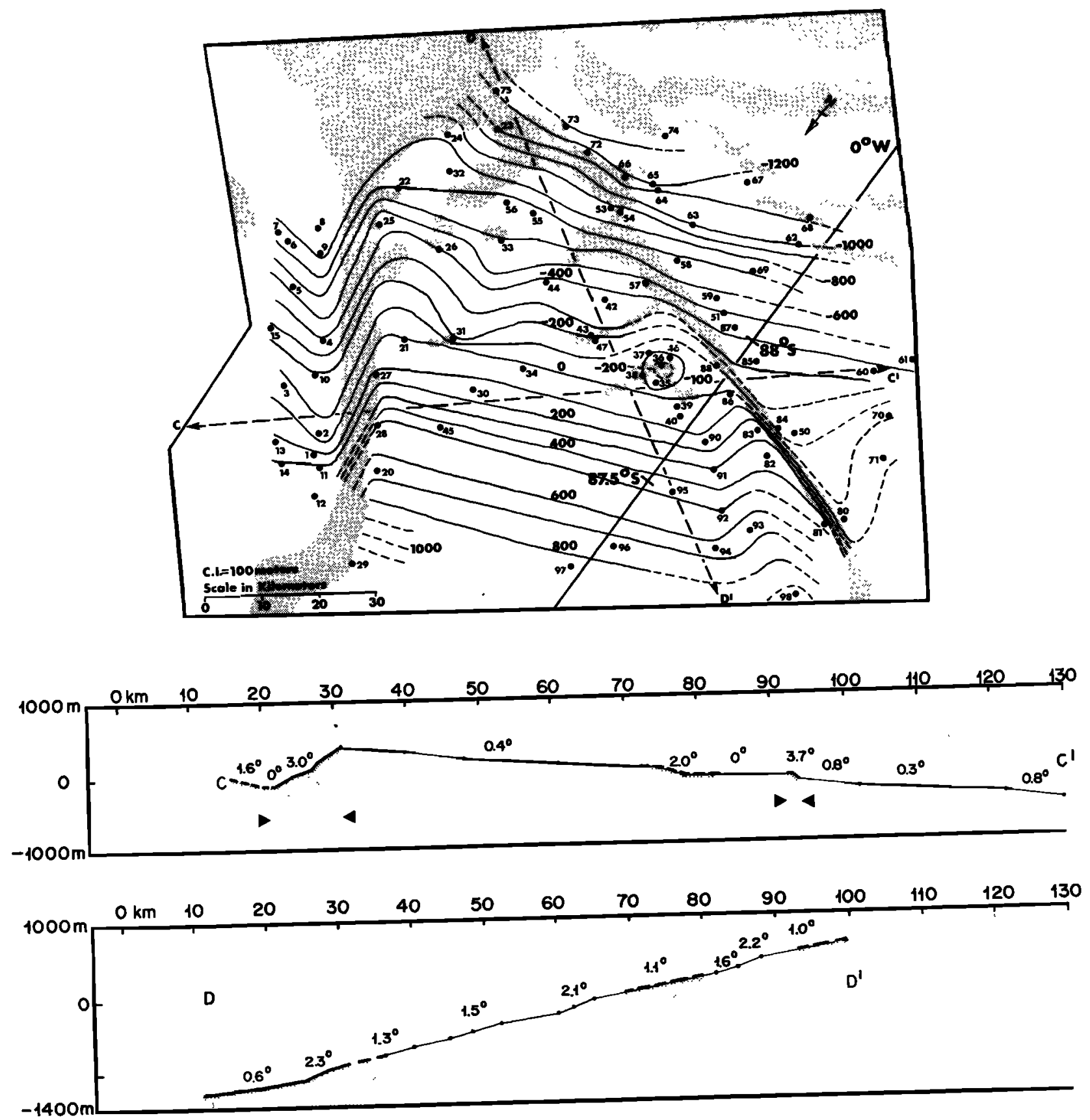

Fig. 8. Model III. Another model of the area included in model II constructed from a different pair of photographs (see Fig. 8. The two models differ mainly by a regional tilt of about $1.3^{\circ}$, which is within the tilt uncertainty discussed in the Table 2). The two models differ mainly by a regional tilt of about 1.3 , whe text. They agree on the height of features associated with the dark bands to within

point locations for which relative elevations have been calculated (see Tab in $100 \mathrm{~m}$.

metric troughs, oriented in such a way that their steepest slope is outward-facing from the central topographic high near $87^{\circ} \mathrm{S}, 0^{\circ} \mathrm{W}$

Models I-V indicate that the south polar bands slope $1^{\circ}-5^{\circ}$ and are $100-1000 \mathrm{~m}$ high. Figure 13 emphasizes the extreme subtlety of slopes associated with the bands. From the profiles, roughly $90 \%$ of the surface within the cap and sloping $2^{\circ}$ or more outward from the central high is partially or totally defrosted. The only two exceptions occur in model Ill and may result from improper tilt orientation of the entire model. This is consistent with model II of the same area, which differs from model III by a regional tilt of $1.3^{\circ}$ and exhibits no such excep- tions. In models I-V, only about $30 \%$ of the area sloping inward or less than $2^{\circ}$ outward from the central high shows evidence of defrosting. Exceptions to these two generalizations, such as partial defrosting of apparently level ground in Models $I$ and II, may result from averaging of local slopes over areas large compared to the dimension of the slopes. Such averaging occurs whenever the data network is not sufficiently dense to resolve individual slopes or where the surface is rough at a scale below the limit of photogrammetric resolution. Note that the above observations do not preclude defrosting of sufficiently steep poleward-facing slopes, as illustrated near $88^{\circ}-89^{\circ} \mathrm{S}, 0^{\circ} \mathrm{W}$ (Figure 3 ). 


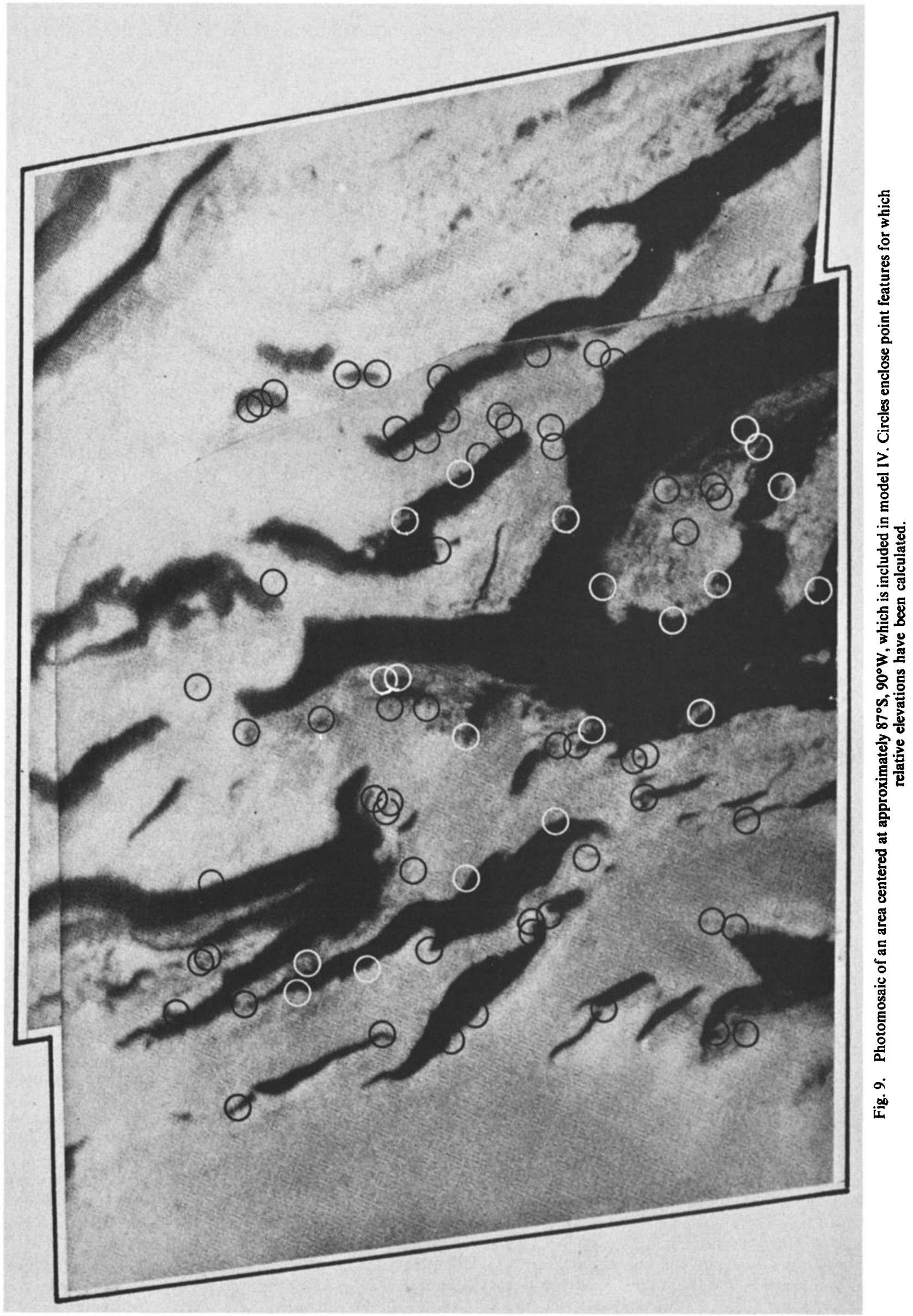



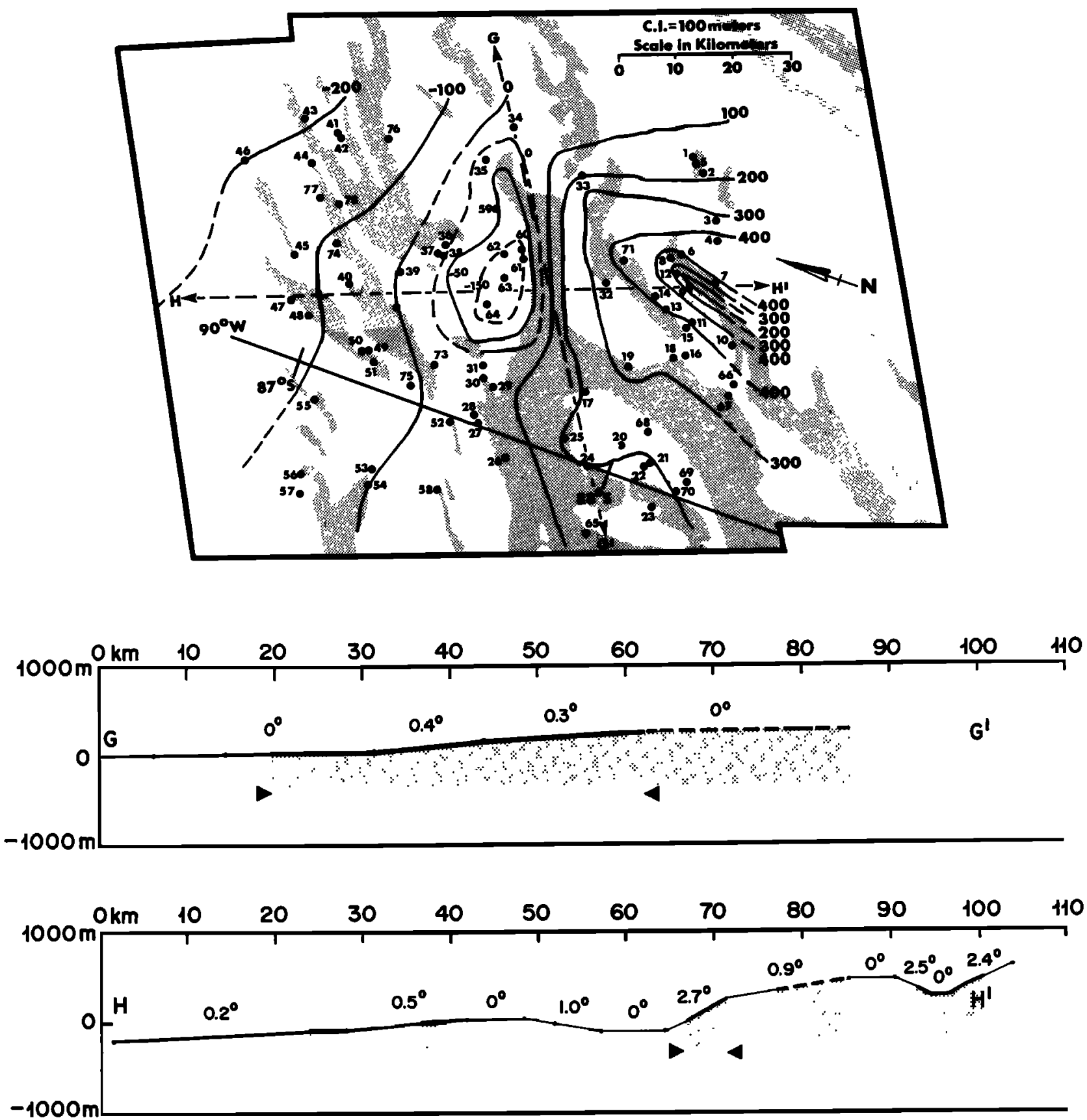

Fig. 10. Model IV. Photogrammetric model showing a variety of topographic forms, including an apparent closed depression near the center. The dark band at about $300-\mathrm{m}$ elevation in the lower right is the same feature as the major scarp shown in Figures 11 and 12. Elevations of the control points indicated by numbered circles are listed in Table 7. Vertical exaggeration in the profiles is $10: 1$; horizontal scale is slightly expanded relative to photomosaic. Contour interval is $100 \mathrm{~m}$.

Taken collectively, the available topographic data suggest that the south polar layered deposits attain a maximum thickness of $1-2 \mathrm{~km}$ at a point near $87^{\circ} \mathrm{S}, 0^{\circ} \mathrm{W}$. From the UVS data and generalized A frame map (Figure 3), the net relief from the lowest point in the polar basin to the highest point of the layered deposits is approximately $4.5 \mathrm{~km}$. The basin relief in unlayered sections, measured from the floor to the top of the heavily cratered northern rim, is about $3 \mathrm{~km}$ (UVS). Thus assuming comparable relief for the buried portion of the basin, 1-2 $\mathrm{km}$ of relief can be attributed to the presence of the layered deposits. Under the unlikely assumption that the basin exhibits no relief where buried by the layered deposits, a max- imum thickness of $4.5 \mathrm{~km}$ could be attributed to the deposits.

\section{North Polar Region}

Topographic information concerning the north polar layered deposits is limited to a set of three occultation points (Table 1, Figure 1), an A frame photogrammetric model (model B of Table 2; Table 9; Figures 14, 15), and a single high-resolution B frame model (model VI of Table 2; Table 10; Figures 16, 17). Taken together, the occultation and $A$ frame photogrammetric data imply that the surface of the north polar layered deposits lies at planetocentric distances ranging from 3371 to $3379 \mathrm{~km}$ at corresponding atmospheric pressures 
TABLE 7. Stereo Model IV

\begin{tabular}{|c|c|c|c|c|c|}
\hline $\begin{array}{c}\text { Control } \\
\text { Point }\end{array}$ & $\begin{array}{c}\text { Elevation Relative } \\
\text { to Point 39, } \\
\text { m }\end{array}$ & $\begin{array}{c}\text { Control } \\
\text { Point }\end{array}$ & $\begin{array}{c}\text { Elevation Relative } \\
\text { to Point 39, } \\
\text { m }\end{array}$ & $\begin{array}{c}\text { Control } \\
\text { Point }\end{array}$ & $\begin{array}{c}\text { Elevation Relative } \\
\text { to Point } 39 \\
\text { m }\end{array}$ \\
\hline 1 & 180 & 27 & 100 & 53 & 20 \\
\hline 2 & 160 & 28 & 70 & 54 & -30 \\
\hline 3 & 350 & 29 & 90 & 55 & -30 \\
\hline 4 & 430 & 30 & 130 & 56 & -30 \\
\hline 5 & 210 & 31 & 150 & 57 & -80 \\
\hline 6 & 460 & 32 & 350 & 58 & 30 \\
\hline 7 & 400 & 33 & 290 & 59 & -50 \\
\hline 8 & 160 & 34 & 80 & 60 & -270 \\
\hline 9 & 190 & 35 & -40 & 61 & -110 \\
\hline 10 & 350 & 36 & -80 & 62 & -200 \\
\hline 11 & 400 & 37 & -80 & 63 & -100 \\
\hline 12 & 280 & 38 & -60 & 64 & -230 \\
\hline 13 & 475 & 39 & 0 & 65 & 120 \\
\hline 14 & 440 & 40 & -60 & 66 & 420 \\
\hline 15 & 400 & 41 & -200 & 67 & 375 \\
\hline 16 & 340 & 42 & -170 & 68 & 250 \\
\hline 17 & 200 & 43 & -150 & 69 & 150 \\
\hline 18 & 340 & 44 & -170 & 70 & 230 \\
\hline 19 & 360 & 45 & -130 & 71 & 525 \\
\hline 20 & 140 & 46 & 190 & 72 & -130 \\
\hline 21 & 260 & 47 & -140 & 73 & 30 \\
\hline 22 & 260 & 48 & -110 & 74 & -50 \\
\hline 23 & 170 & 49 & -120 & 75 & -60 \\
\hline 24 & 200 & 50 & -130 & 76 & -160 \\
\hline 25 & 220 & 51 & -130 & 77 & -130 \\
\hline 26 & 75 & 52 & 60 & 78 & -175 \\
\hline
\end{tabular}

of 5.0-7.6 mbar (from equation (1)). Similarly, the surface of the northern residual frost cap is calculated to reside at 3373 to $3379 \mathrm{~km}$ at pressures ranging from 5.0 to $7.0 \mathrm{mbar}$.

In the north the $A$ frame model indicates two distinct topographic highs centered near $90^{\circ} \mathrm{N}$ and $83^{\circ} \mathrm{N}, 0^{\circ} \mathrm{W}$. These locations correlate with what appear to be two centers of concentric dark banding visible in Figure 14. In other Mariner 9 photographs taken before final retreat of the north polar seasonal cap (e.g., DAS 12013129) the mottled area covered by the high-resolution B frame model appears morphologically typical of the entire residual cap. The general trend of surface gradients descending from two central highs, combined with details of the B frame model, suggests a series of gentle outward-facing scarps descending stepwise from local topographic highs. The B frame model indicates that these north polar features are $200-1000 \mathrm{~m}$ high and exhibit slopes of

TABLE 8. Stereo Model V

\begin{tabular}{|c|c|c|c|c|c|}
\hline $\begin{array}{c}\text { Control } \\
\text { Point }\end{array}$ & $\begin{array}{c}\text { Elevation Relative } \\
\text { to Point } 53, \\
\text { m }\end{array}$ & $\begin{array}{c}\text { Control } \\
\text { Point }\end{array}$ & $\begin{array}{c}\text { Elevation Relative } \\
\text { to Point } 53, \\
\text { m }\end{array}$ & $\begin{array}{c}\text { Control } \\
\text { Point }\end{array}$ & $\begin{array}{c}\text { Elevation Relative } \\
\text { to Point } 53, \\
\text { m }\end{array}$ \\
\hline 1 & 340 & 35 & 285 & 64 & -100 \\
\hline 2 & 360 & 36 & 220 & 67 & -100 \\
\hline 3 & 360 & 37 & 185 & 68 & -155 \\
\hline 4 & 310 & 38 & 200 & 69 & -260 \\
\hline 5 & 250 & 39 & 100 & 71 & -100 \\
\hline 6 & 170 & 40 & 150 & 73 & -25 \\
\hline 8 & 200 & 41 & 125 & 74 & 25 \\
\hline 9 & 160 & 42 & 100 & 75 & 130 \\
\hline 10 & 70 & 43 & 60 & 76 & 150 \\
\hline 11 & 175 & 45 & 115 & 77 & 180 \\
\hline 12 & 75 & 46 & 50 & 78 & -230 \\
\hline 13 & 175 & 47 & -120 & 79 & -240 \\
\hline 14 & 150 & 51 & -50 & 80 & -180 \\
\hline 16 & 75 & 52 & -25 & 81 & -180 \\
\hline 17 & 125 & 53 & 0 & 82 & -200 \\
\hline 19 & 150 & 54 & -50 & 83 & -265 \\
\hline 20 & 25 & 55 & 180 & 85 & -715 \\
\hline 23 & -25 & 56 & 180 & 86 & -775 \\
\hline 25 & -45 & 57 & 155 & 87 & -750 \\
\hline 26 & 50 & 58 & -25 & 88 & -1050 \\
\hline 28 & 160 & 59 & -30 & 89 & -1010 \\
\hline 29 & 160 & 62 & -60 & 90 & -800 \\
\hline 33 & 200 & 63 & -40 & 92 & -1000 \\
\hline 34 & 200 & & & & \\
\hline
\end{tabular}




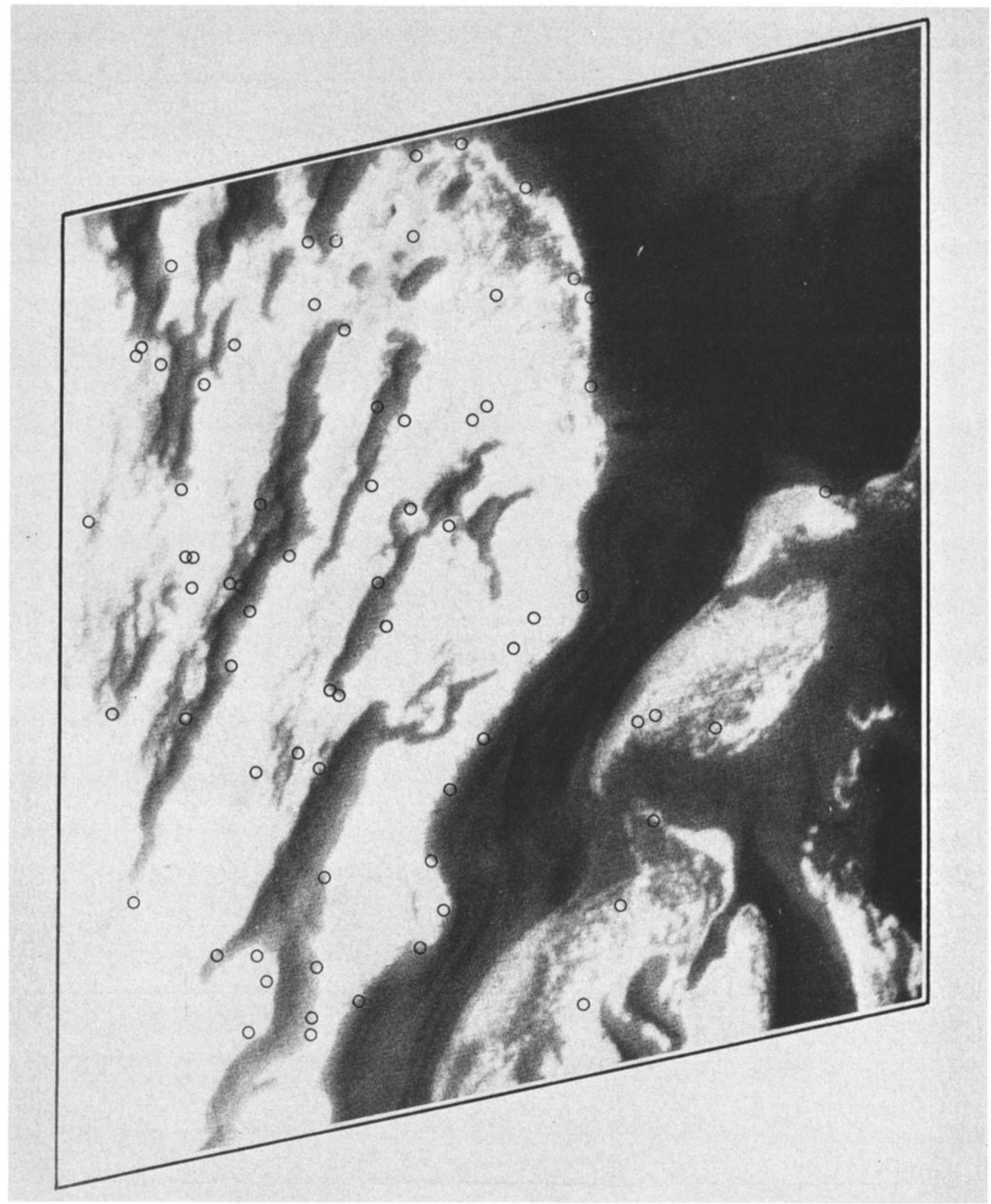

Fig. 11. Photograph of an area centered at approximately $89^{\circ} \mathrm{S}, 90^{\circ} \mathrm{W}$, for which high-resolution topography is presented in Figure 12. Note the major layered scarp and several roughly parallel dark features which suggest topographic control of defrosting. Circles enclose point features for which relative elevations have been calculated. 

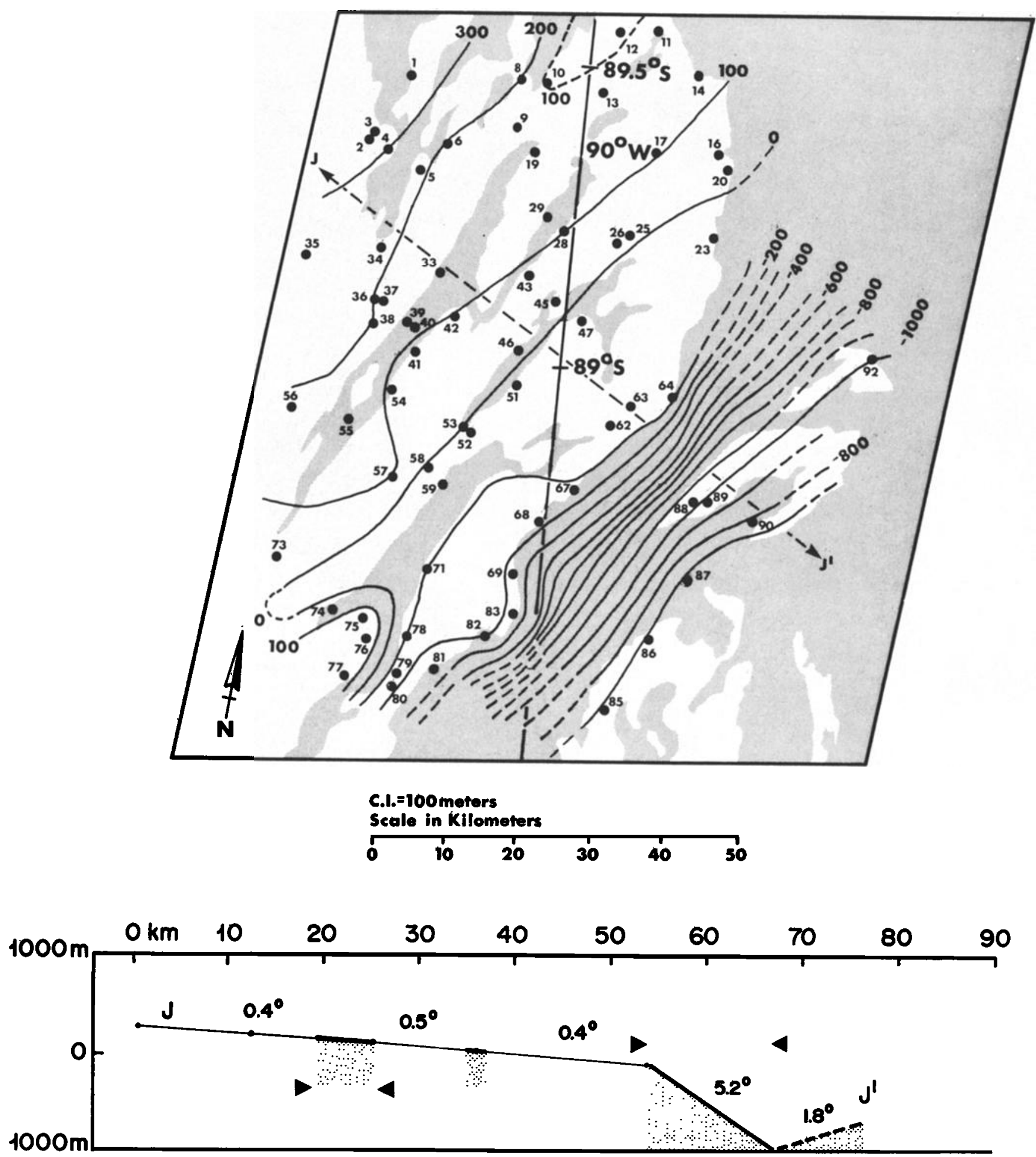

Fig. 12. Model V. Photogrammetric model of a major layered scarp at $89^{\circ} \mathrm{S}, 90^{\circ} \mathrm{W}$. Elevations of control points indicated by numbered circles are listed in Table 8 . Vertical exaggeration in the profile is $10: 1$; horizontal scale is slightly expanded relative to photograph. Contour interval is $100 \mathrm{~m}$. 
Vertical Exaggeration $=10 x$

No Vertical Exoggeration

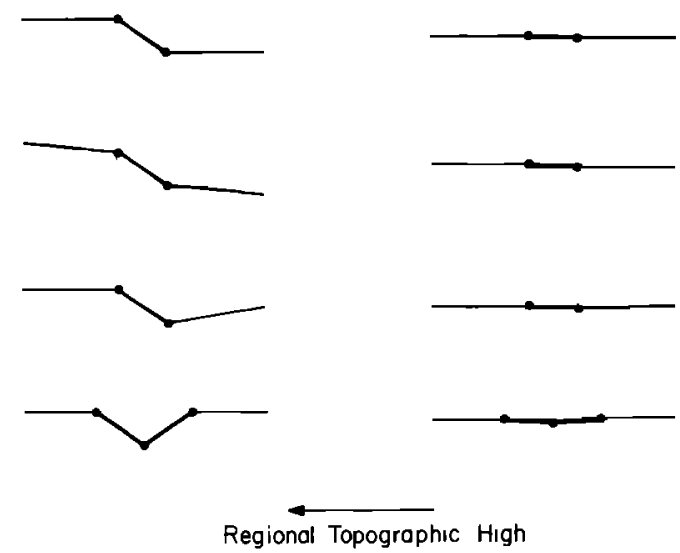

Fig. 13. Generalized topographic features of the south polar layered deposits illustrating the progression from outward-facing scarp to symmetric trough. Note the extreme subtlety of associated heights and slopes. Heavy lines denote defrosted areas.

a few degrees, consistent with similar features seen in the south. In the B frame profile, virtually $100 \%$ of the surface within the residual cap and sloping outward $2^{\circ}$ or more is partially or totally defrosted. In contrast, only about $35 \%$ of the area sloping inward or less than $2^{\circ}$ outward is defrosted. By extrapolating a plane under the layered deposits from their perimeter, we estimate the net thickness of the northern deposits to be $4-6 \mathrm{~km}$.

\section{Discussion AND SUMmary}

Returning to the framework established at the outset of the paper, we now discuss implications of the topographic data bearing directly on the behavior of polar volatiles and the topographic form of the polar layered deposits.

\section{Implications for the Behavior of Volatiles}

High-resolution photogrammetric models of both residual frost caps reveal that in general localized defrosting correlates with a series of outward-facing slopes associated with gentle topographic undulations within the polar layered deposits.
Although the topographic data are not sufficiently detailed to permit point-by-point comparisons of intercepted solar flux, observed slopes are in general consistent with the suggestion by Murray et al. [1972] that defrosting is controlled by increased solar insolation collected on outward-facing slopes within the layered deposits. However, other processes such as differential erosion of frost along outward-facing slopes or slope-dependent meteorological effects (e.g., 'chinook' winds associated with the eastern Rocky Mountains) could conceivably contribute to the observed defrosting.

This analysis indicates that the south polar layered deposits lie almost entirely at greater elevations than the northern deposits, at variance with a preliminary suggestion by Soderblom et al. [1973] that the highest surfaces of each may lie at the same altitude. Height ranges associated with the residual frost caps in both polar regions confirm the conclusion by Murray and Malin [1973b] that the south polar residual cap lies entirely higher (at lower pressure) than its northern counterpart. Ward et al. [1974] have shown that such an elevation difference would cause any hypothetical surface deposit of carbon dioxide in the south to migrate to the north in less than about $2 \times 10^{3}$ years in the absence of some ad hoc mechanism for cooling the south pole relative to the north pole. Since no evidence for such a mechanism exists and since the above time scale is short compared to the short-term obliquity oscillation time scale $\left(1.2 \times 10^{5}\right.$ years $)$, it is doubtful that a perennial $\mathrm{CO}_{2}$ ice cap would ever form at the south pole. Thus the south pole is an unlikely site for any perennial surface deposit of solid $\mathrm{CO}_{2}$ and the residual south polar cap is most likely composed of water ice [Murray and Malin. 1973b; Ward et al., 1974].

Finally, a regional slope of less than $1^{\circ}$ in the vicinity of the south pole may serve to shift the point of minimum annual solar insolation away from the pole and thus account for the observed offset of the southern residual cap. Combined with the fact that increased insolation collected on relatively low local slopes is apparently responsible for defrosting the dark bands, this argues that stability of the volatile involved is largely insolation controlled. Location of the cap on a regional topographic high (and consequent pressure low) is evidence that pressure stability is not the critical factor in the offset. This is also consistent with the conclusion that the cap is most likely composed of $\mathrm{H}_{2} \mathrm{O}$ and not $\mathrm{CO}_{2}$ ice.

TABLE 9. Stereo Model B

\begin{tabular}{cccccccc}
\hline $\begin{array}{c}\text { Control } \\
\text { Point }\end{array}$ & $\begin{array}{c}\text { Elevation, } \\
\mathrm{km}\end{array}$ & $\begin{array}{c}\text { Control } \\
\text { Point }\end{array}$ & $\begin{array}{c}\text { Elevation, } \\
\mathrm{km}\end{array}$ & $\begin{array}{c}\text { Control } \\
\text { Point }\end{array}$ & $\begin{array}{c}\text { Elevation, } \\
\mathrm{km}\end{array}$ & $\begin{array}{c}\text { Control } \\
\text { Point }\end{array}$ & $\begin{array}{c}\text { Elevation, } \\
\mathrm{km}\end{array}$ \\
\hline 1 & -9.8 & 21 & -4.8 & 41 & -3.2 & 61 & -1.0 \\
2 & -9.3 & 22 & -4.4 & 42 & -5.2 & 62 & 3.4 \\
3 & -6.0 & 23 & -4.1 & 43 & -9.6 & 63 & 2.9 \\
4 & -5.8 & 24 & -4.6 & 44 & -7.4 & 64 & 3.2 \\
5 & -6.7 & 25 & -3.0 & 45 & -7.5 & 65 & 3.2 \\
6 & -4.0 & 26 & -3.7 & 46 & 3.1 & 66 & -0.6 \\
7 & -3.5 & 27 & -2.8 & 47 & 0.8 & 67 & 1.0 \\
8 & -4.4 & 28 & 0.4 & 48 & 1.0 & 68 & 0.2 \\
9 & -12.0 & 29 & 0.9 & 49 & -5.9 & 69 & 1.2 \\
10 & -6.3 & 30 & 3.4 & 50 & -6.2 & 70 & 1.2 \\
11 & -10.0 & 31 & 0.2 & 51 & 1.6 & 71 & 1.5 \\
12 & -9.5 & 32 & -1.5 & 52 & -5.3 & 72 & 1.7 \\
13 & -12.3 & 33 & -1.0 & 53 & -5.7 & 73 & 1.8 \\
14 & -11.7 & 34 & -0.4 & 54 & -2.5 & 74 & 2.1 \\
15 & -11.2 & 35 & 0.1 & 55 & -2.4 & 75 & 0.5 \\
16 & -6.0 & 36 & -1.7 & 56 & -0.4 & 76 & -1.0 \\
17 & -1.9 & 37 & -0.3 & 57 & -6.2 & 77 & 1.0 \\
18 & -2.5 & 38 & -0.2 & 58 & -5.4 & 78 & 0.7 \\
19 & -2.9 & 39 & -0.3 & 59 & -2.3 & 79 & 3.0 \\
20 & -4.3 & 40 & -2.8 & 60 & -2.6 & 80 & 2.5 \\
\hline
\end{tabular}




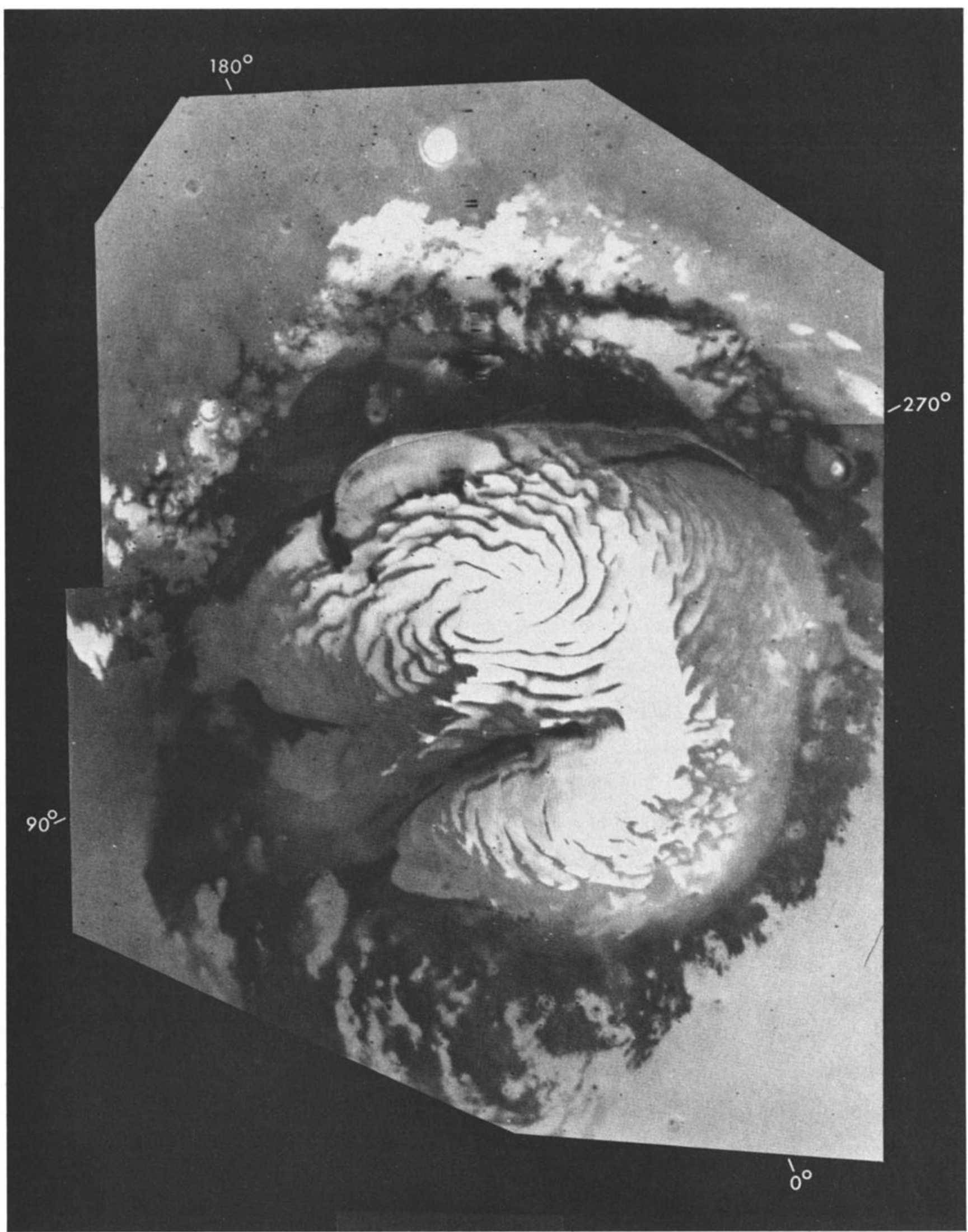

Fig. 14. Photomap of the north polar residual frost cap at $\mathbf{A}$ frame resolution illustrating its banded appearance and distinctive bimodal form. Topographic information indicates that the bands arise from defrosting of a series of outwardfacing scarps descending steplike from two central topographic highs centered at $90^{\circ} \mathrm{N}$ and $83^{\circ} \mathrm{N}, 0^{\circ} \mathrm{W}$, respectively. Two photographs which comprise the mosaic have been computer enhanced at the Image Processing Lab of NASA's Jet Propulsion Laboratory. 


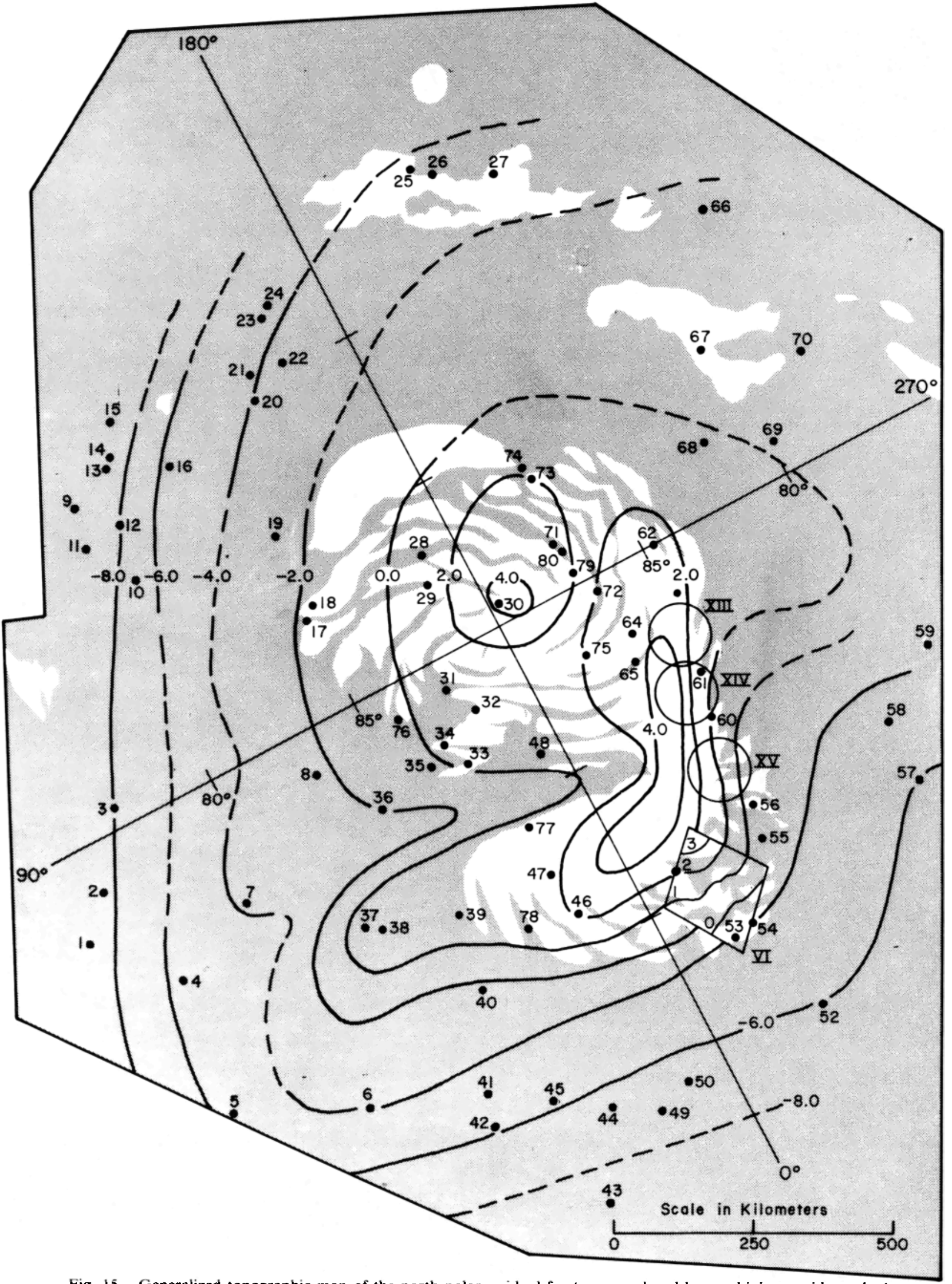

Fig. 15. Generalized topographic map of the north polar residual frost cap produced by combining a wide-angle A frame model (model B) with a single high-resolution B frame model (model VI). Included are the locations of three radio occultation points for which absolute radii and associated surface pressures are listed in Table 1. The original model has been tilted about $0.3^{\circ}$ around the axis defined by the occultation points, so that the boundaries of the layered deposits at the top and bottom of the model now lie at the same height. Point elevations for model B are listed in Table 9. Planetary curvature associated with a spherical planet with a radius of $3379 \mathrm{~km}$ has been removed from both models. Contour interval is $2 \mathrm{~km}$. 


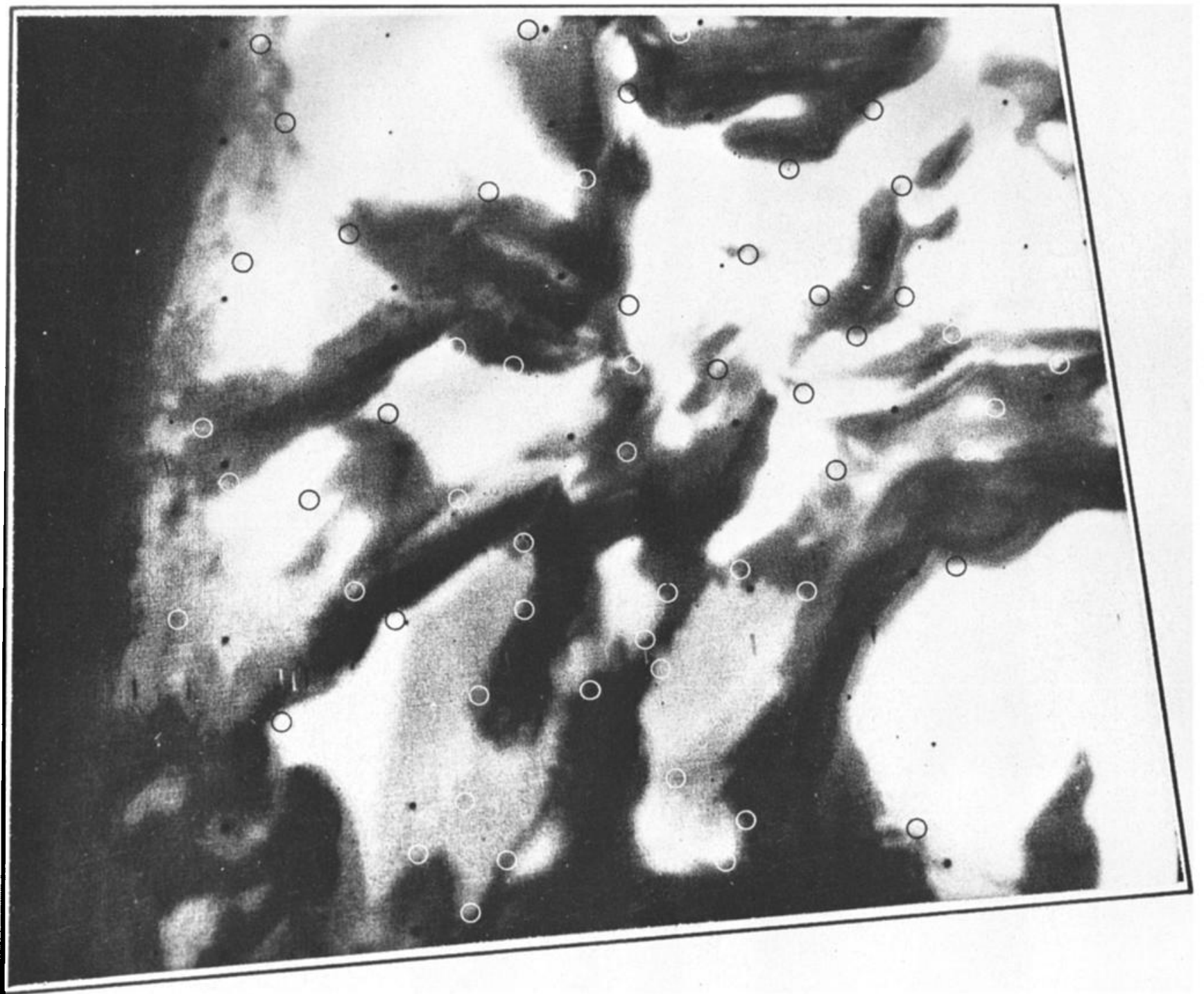

Fig. 16. Photograph of one area in the north polar region for which high-resolution topography was obtained. Circles enclose features for which relative elevations have been calculated.

TABLE 10. Stereo Model VI

\begin{tabular}{cccccc}
\hline $\begin{array}{c}\text { Control } \\
\text { Point }\end{array}$ & $\begin{array}{c}\text { Elevation Relative } \\
\text { to Point 5, } \\
\mathrm{m}\end{array}$ & $\begin{array}{c}\text { Control } \\
\text { Point }\end{array}$ & $\begin{array}{c}\text { Elevation Relative } \\
\text { to Point 5, } \\
\mathrm{m}\end{array}$ & $\begin{array}{c}\text { Control } \\
\text { Point }\end{array}$ & $\begin{array}{c}\text { Elevation Relative } \\
\text { to Point 5, } \\
\text { m }\end{array}$ \\
\hline 1 & -300 & 20 & 2550 & 39 & 1150 \\
2 & 600 & 21 & 2150 & 40 & 1800 \\
3 & 250 & 22 & 2100 & 41 & 1550 \\
4 & 1050 & 23 & 2000 & 42 & 1400 \\
5 & 0 & 24 & 1950 & 43 & 1550 \\
6 & -100 & 25 & 800 & 44 & 2350 \\
7 & 150 & 26 & 1000 & 45 & 2150 \\
8 & 650 & 27 & 1100 & 46 & 1750 \\
9 & 800 & 28 & 1100 & 47 & 2150 \\
10 & 1650 & 29 & 700 & 48 & 2000 \\
11 & 1950 & 31 & 850 & 49 & 3050 \\
12 & 1050 & 32 & 1050 & 50 & 3450 \\
13 & 1300 & 33 & 550 & 51 & 2150 \\
14 & 1100 & 34 & 300 & 52 & 1850 \\
15 & 2100 & 35 & 650 & 53 & 2350 \\
16 & 2350 & 36 & 400 & 54 & 2100 \\
17 & 2100 & 37 & 900 & 55 & 2350 \\
18 & 2500 & 38 & 950 & 56 & 1650 \\
19 & 2550 & & & 57 & 1700 \\
\hline
\end{tabular}




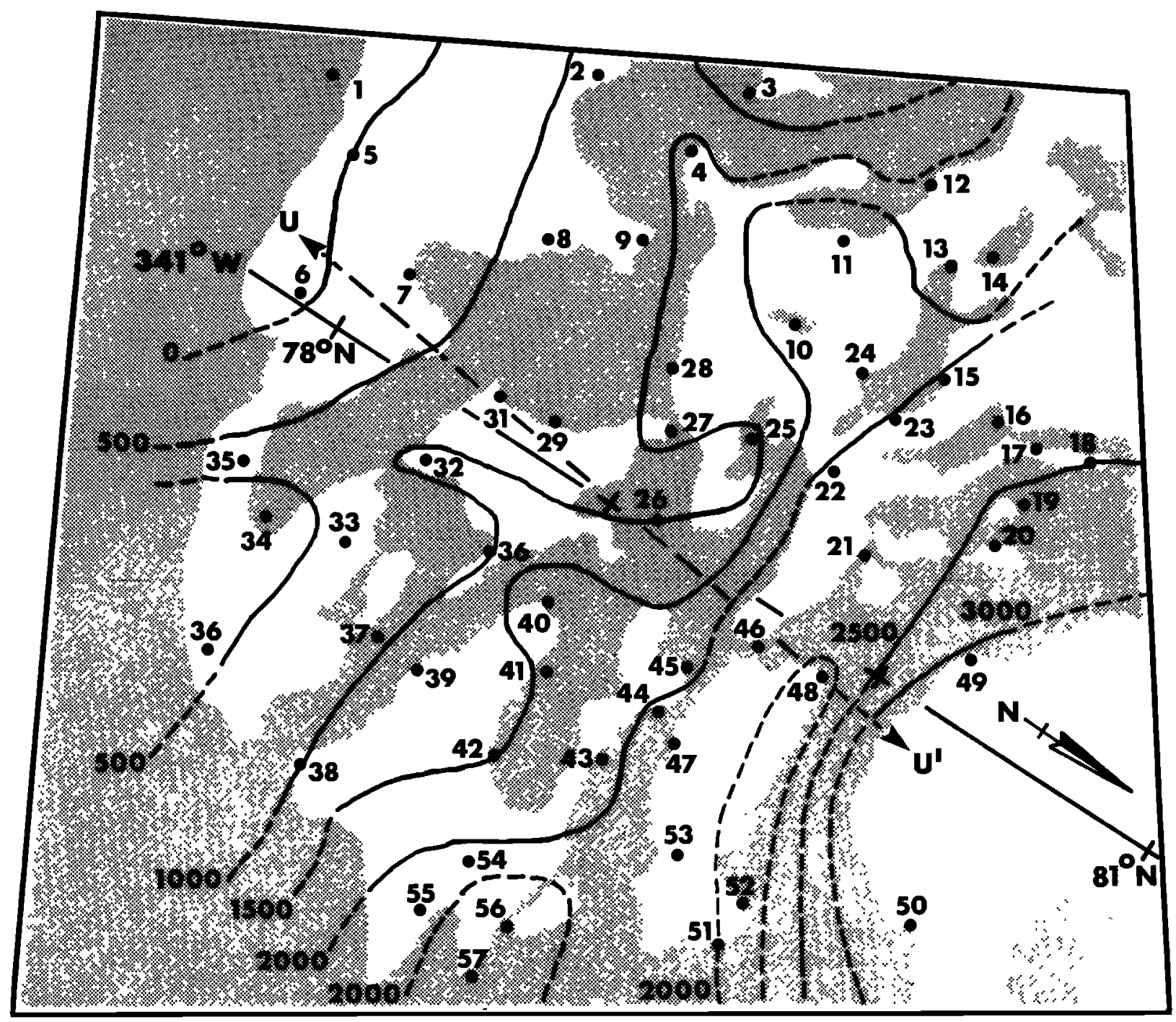

\section{Scale in Kllometers}

O40

C.I. $=500$ meters

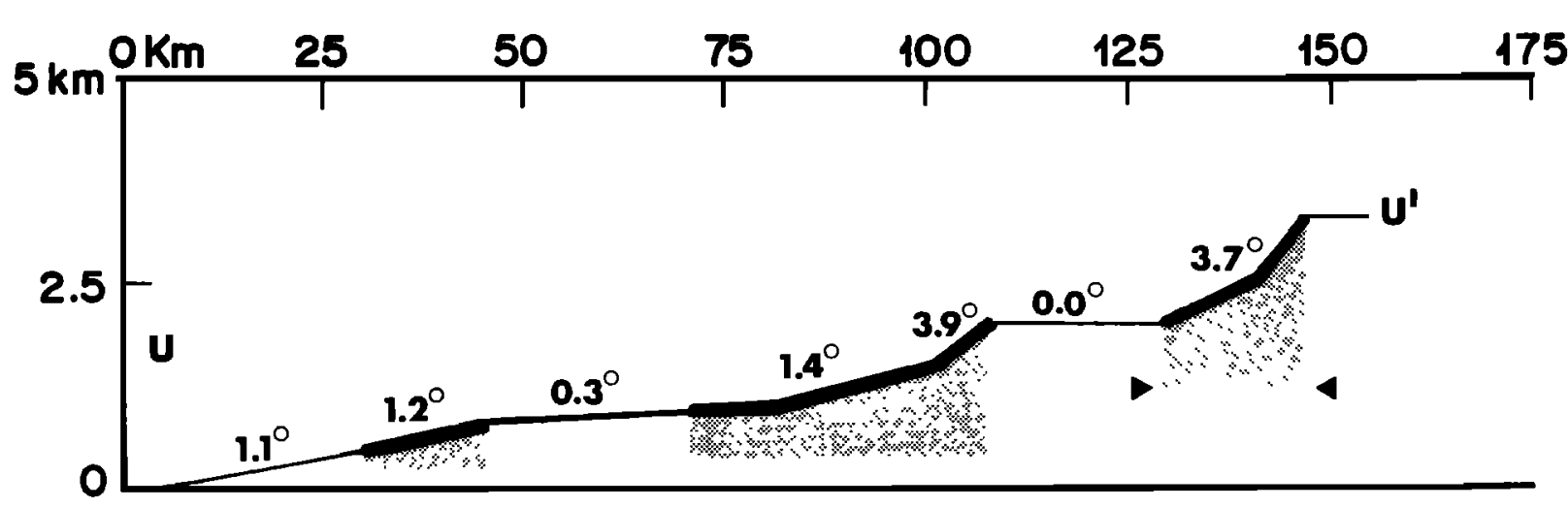

Fig. 17. Model VI. Photogrammetric model of the north polar area centered at approximately $79^{\circ} \mathrm{N}, 345^{\circ} \mathrm{W}$. Note the apparent steplike morphology and topographic control of defrosting indicated by the profile. Note also the large amount of relief across the dark areas compared to similar features in the south. Elevations of control points indicated by numbered circles are listed in Table 10. Vertical exaggeration in the profile is $10: 1$; horizontal scale is slightly expanded relative to photograph. Contour interval is $500 \mathrm{~m}$. 
Topographic Configuration of the Polar

\section{Layered Deposits}

Consistent with the data already presented, we offer the following semiquantitative topographic description of the polar layered deposits. In both the north and the south a series of regularly spaced outward-facing topographic undulations sloping from $1^{\circ}-5^{\circ}$ and ranging in height from 100 to $1000 \mathrm{~m}$ descend from central topographic highs. In the south a single high is centered near $87^{\circ} \mathrm{S}, 0^{\circ} \mathrm{W}$, while the north displays a pair of distinct highs centered near $90^{\circ} \mathrm{N}$ and $83^{\circ} \mathrm{N}, 0^{\circ} \mathrm{W}$, respectively. Topographic features within the south polar layered deposits exhibit the full range of morphologies from trough to scarp, while observed features of the northern deposits appear to be more exclusively scarplike. However, the apparent difference could result from limited stereo coverage of the northern deposits.

Cutts [1973a] has pointed to the westward curvature of large erosional reentrants within the south polar basin and between the lobes of the north polar residual cap as evidence for the action of Coriolis-affected polar winds. Dark bands in the north polar residual cap exhibit exclusively eastward curvature, while similar features in the southern cap exhibit both eastward and westward curvature (Figures 2 and 14). It seems unlikely therefore that topographic features represented by the bands can generally be ascribed to aeolian erosion by Coriolisaffected winds. The suggestion by Cutts [1973a] that a more complex wind pattern near the poles may be responsible for erosion of the dark bands remains a viable but purely speculative alternative.

Layered deposits in each polar region lie at significantly different planetocentric distances, the southern deposits lying almost entirely above their northern counterparts. Total thickness of the polar deposits is $1-2 \mathrm{~km}$ in the south and 4-6 $\mathrm{km}$ in the north.

The topographic configuration of the polar deposits which emerges from the Mariner 9 data is more complex than would be expected from either the purely constructional model of Murray and Malin [1973a] or from the purely erosional model of Cutts [1973a]. More realistic genesis models for the deposits probably require both constructional and erosional processes to account for their observed topographic complexity. Future acquisition of high-quality polar topographic data would contribute to our better understanding of the behavior of polar volatiles and the genesis of the polar layered deposits and thus should be a prime goal of future spacecraft missions to Mars.

Acknowledgments. We wish to acknowledge the contributions made by Bruce $\mathrm{C}$. Murray and Michael $\mathrm{C}$. Malin during many hours of animated discussion. We also thank Clark R. Chapman, James A. Cutts, Charles W. Hord, Andrew P. Ingersoll, Carl Sagan, and Robert P. Sharp for their careful reviews of the manuscript. The generosity displayed by Hord and Pang in consenting to our presentation of their preliminary results is especially noteworthy. Special thanks are also due to Jurrie J. van der Woude for his patience and skill in the preparation of illustrations and to the personnel of the Image Processing Lab of NASA's Jet Propulsion Laboratory for their expert assistance in the computer enhancement of images used in the paper. This work represents one phase of research being conducted at the Space Photography Laboratory of the California Institute of Technology under NASA grant NGR 05-002-305. Contribution 2410, Division of Geological and Planetary Sciences, California Institute of Technology, Pasadena, California.

\section{REFERENCES}

Blasius, K. R., A study of martian topography by analytic photogrammetry, J. Geophys. Res., 78, 4411, 1973.

Cain, D. L., A. J. Kliore, B. L. Seidel, M. J. Sykes, and P. Woiceshyn, Approximations to the mean surface of Mars and Mars atmosphere using Mariner 9 occultations, J. Geophys. Res., 78, 4352, 1973.

Conrath, B., R. Curran, R. Hanel, V. Kunde, W. Maguire, J. Pearl, J. Pirraglia, J. Welker, and T. Burke, Atmospheric and surface properties of Mars obtained by infrared spectroscopy on Mariner $9, J$. Geophys. Res., 78, 4267, 1973.

Cutts, J. A., Wind erosion in the martian polar regions, J. Geophys. Res., 78, 4211, 1973a.

Cutts, J. A., Nature and origin of layered deposits of the martian polar regions, J. Geophys. Res., 78, 4231, $1973 b$.

Hord, C. W., C. A. Barth, A. I. Stewart, and A. L. Lane, Mariner 9 ultraviolet spectrometer experiment: Photometry and topography of Mars, Icarus, 17, 443, 1972.

Hord, C. W., K. E. Simmons, and L. K. McLaughlin, Mariner 9 ultraviolet spectrometer experiment: Pressure-altitude measure-ments on Mars, Icarus, 21, 292, 1974.

Kliore, A. J., G. Fjeldbo, B. L. Seidel, M. J. Sykes, and P. M. Woiceshyn, $S$ band radio occultation measurements of the atmosphere and topography of Mars with Mariner 9: Extended mission coverage of polar and intermediate latitudes, J. Geophys. Res., $78.4331,1973$.

Murray, B. C., and M. C. Malin, Polar wandering on Mars?, Science, 179, 997, 1973a.

Murray, B. C., and M. C. Malin, Polar volatiles on Mars-Theory vs. observations, Science, 182, 437, 19736 .

Murray, B. C., L. A. Soderblom, J. A. Cutts, R. P. Sharp, D. J Milton, and R. B. Leighton, Geological framework of the south polar region of Mars, Icarus, 17, 328, 1972.

Pang, K., Ultraviolet reflectance of Mars' south polar cap and opacity of the 1971 dust cloud, Annual Meeting of American Astronomical Society Division for Planetary Science, University of Hawaii, Honolulu, Hawaii, March 21-24, 1972.

Soderblom, L. A., M. C. Malin, J. A. Cutts, and B. C. Murray, Mariner 9 observations of the surface of Mars in the north polar region, J. Geophys. Res., 78, 4197, 1973.

Ward, W. R., B. C. Murray, and M. C. Malin, Climatic variations on Mars, 2, Evolution of carbon dioxide atmosphere and polar caps, $J$. Geophys. Res., 79, 3387, 1974.

Wilhelms, D. E., Comparison of martian and lunar multiringed circular basins, J. Geophys. Res., 78, 4084, 1973.

Woiceshyn, P. M., Global seasonal atmospheric fluctuations on Mars, Icarus, 22(3), 325, 1974.

(Received December 12, 1974;

revised March 24, 1975;

accepted March 31, 1975.) 